\title{
PRODUCTIVIDAD, DESIGUALDAD Y CAPITAL HUMANO: LOS COMPLEJOS DESAFÍOS DE CHILE
}

\author{
Harald Beyer
}

Para llegar a ser un país de alto ingreso per cápita hay que acumular capital tanto físico como humano. Esa acumulación no es automática. Por ejemplo, no se trata sólo de aumentar la escolaridad de la población sino que ésta debe venir acompañada de estándares de calidad (llamémoslos aprendizajes y destrezas) mínimos. Si éstos no se logran, la acumulación de capital humano estará muy por debajo de lo que, por ejemplo, sugiere la escolaridad de la población. Algo análogo se puede decir respecto de la acumulación de capital físico. En la medida que, en alguna proporción, ésta sea el fruto de distorsiones en la economía, su efecto sobre el crecimiento será menor de lo que podría desprenderse del análisis independiente de su magnitud.

Por eso es que una mirada meramente cuantitativa de la inversión o de la educación nos entrega una mirada limitada de la capacidad de un país para, por ejemplo, crecer o reducir los niveles de desigualdad. La acumulación de capital tanto físico y humano sirve de poco si los países no son capaces de desarrollar un conjunto de políticas e instituciones que, por una parte, aseguren fehacientemente que los

HARALD BEYER. Investigador y Coordinador Académico del Centro de Estudios Públicos. Ingeniero Comercial, Universidad de Chile. Ph.D. en Economía, Universidad de California, Los Ángeles. 
recursos invertidos serán transformados en capital productivo y, por otra, permitan aprovechar eficientemente ese capital. Las diferencias en el grado de desarrollo de los países tienen mucho que ver con las diferencias en esas instituciones y políticas.

Teniendo esos antecedentes a la vista este estudio reflexiona, a la sombra de un marco general, sobre el desarrollo de la economía chilena en las últimas décadas. En particular se analiza el crecimiento de la misma y la elevada desigualdad que hay en Chile. Se hace ver que en los últimos 50 años la economía chilena ha progresado, en términos relativos, de manera aún insuficiente, y se plantea que sigue siendo un desafío acumular capital. Se hace un análisis especial de las deficiencias educacionales por su impacto tanto en la acumulación de capital humano como en la desigualdad de los ingresos.

\section{Introducción}

$\mathrm{L}_{\mathrm{a}}$

pregunta de por qué algunos países son ricos y otros pobres ha sido central desde, por lo menos, los tiempos de Adam Smith. No podría ser de otra manera porque las diferencias para la población de vivir en un grupo u otro de países son enormes. La pregunta cobra relevancia con el paso del tiempo porque si fijamos como punto de partida el año 1776, año en que se publica "La Investigación en la Naturaleza y Causas de la Riqueza de las Naciones", las diferencias de ingreso per cápita entre países no han hecho más que aumentar. De acuerdo a Maddison (2001), hacia 1820 Europa Occidental tenía un ingreso per cápita promedio de 1.232 dólares (medido en dólares de 1990 ajustados por poder de compra) ${ }^{1}$, América Latina de 665 dólares y África de 418. En promedio los países ricos tenían un ingreso per cápita que triplicaba al de los países pobres. Hacia fines del siglo 20 los países europeos tenían un ingreso per cápita que se acercaba a los 18 mil dólares mientras que los latinoamericanos se empinaban a los 4.350 y los africanos sólo a los 1.370 dólares. Ahora en promedio los países más ricos tienen un ingreso per cápita que, excluyendo los extremos, es 20 veces mayor que el de los países pobres.

Estas diferencias, en su gran mayoría, no se produjeron durante el siglo XIX sino que, en gran medida, como veremos en la tercera sección, se amplificaron durante la segunda mitad del siglo pasado. Ese período distinguió claramente entre los países que se quedaron fuera del carro del

\footnotetext{
${ }^{1}$ La metodología se explica en Maddison (2001), especialmente páginas 170-175.
} 
desarrollo de aquellos que se subieron. Chile, como veremos, no se subió con propiedad, pero tampoco se quedó abajo, debido en gran parte al desempeño que exhibió en el último cuarto del siglo. El desafío en las próximas décadas es mantener el ritmo de los últimos años más que el promedio de las últimas décadas. Es en este contexto donde parece jugar un papel clave la acumulación de capital humano del país y, especialmente, el crecimiento de la productividad.

Voy a tratar de argumentar, de una manera informal, que ambos fenómenos pueden tener una retroalimentación significativa, especialmente por el freno que puede imponer la falta de capital humano al desarrollo de nuevos procesos productivos y, a través de esta vía, a las ganancias de productividad que puede generar la economía. Éstas, después de todo, provienen en una proporción importante de un mejor uso de los recursos productivos. Para ver esto de una manera simplificada piénsese la economía de una forma muy descentralizada. En ese caso, a nivel de una planta el valor del producto tiene que ser igual al pago a los factores productivos ${ }^{2}$. Para una planta i, por ejemplo, tiene que ser cierto que:

$$
\mathrm{P}_{\mathrm{i}}^{*} \mathrm{q}_{\mathrm{i}}=\mathrm{w}_{\mathrm{i}}^{*} \mathrm{~L}_{\mathrm{i}}+\mathrm{r}_{\mathrm{i}}^{*} \mathrm{~K}_{\mathrm{i}}
$$

donde $P_{i}$ y $q_{i}$ representan el precio y la cantidad de producto, respectivamente. Por otra parte, $w_{i}$ y $r_{i}$ representan el precio del trabajo (L) y del capital (K), respectivamente. Sin que ello afecte este planteamiento nos hemos limitado a sólo dos factores productivos. El producto de una economía corresponde a la suma de los valores producidos por todas las plantas existentes. Entonces, la producción de la economía (si se quiere el PIB de ella) se puede representar como sigue:

$$
\sum_{i=1}^{n} \mathrm{p}_{\mathrm{i}} \mathrm{y}_{\mathrm{i}}=\sum_{i=1}^{n} \mathrm{w}_{\mathrm{ili}}+\sum_{i=1}^{n} \rho_{\mathrm{iki}}
$$

donde $\mathrm{n}$ representa el número de plantas existentes en la economía. Es importante recordar que la medida aquí definida no es una de ventas de la empresa sino de valor agregado. Si se quiere introducir algún grado de dinamismo a esta economía simplificada en el contexto de lo que se está planteando y se mantiene el supuesto de que el valor del producto se destina íntegramente al pago de los factores productivos, se puede plantear

${ }^{2}$ Por supuesto, asumiendo que hay retornos constantes a la escala, esto es que el valor del producto se destina íntegramente al pago de los insumos productivos. 
que los cambios totales en el valor del producto tienen que ser compensados por cambios en los pagos a los factores productivos tal como se señala en la expresión siguiente, donde el símbolo $\Delta$ representa variación en la variable que lo acompaña (como siempre, son cambios pequeños):

$$
\sum_{i=1}^{\mathrm{n}} \mathrm{p}_{i} \Delta \mathrm{y}_{\mathrm{i}}+\sum_{i=1}^{n} \mathrm{y}_{\mathrm{i}} \Delta \mathrm{p}_{\mathrm{i}}=\sum_{\mathrm{i}=1}^{n} \mathrm{w}_{\mathrm{i}} \Delta \mathrm{li}_{\mathrm{i}}+\sum_{i=1}^{n} \mathrm{li}_{\mathrm{i}} \Delta \mathrm{w}_{\mathrm{i}}+\sum_{i=1}^{\mathrm{n}} \mathrm{\rho}_{\mathrm{i}} \Delta \mathrm{k}_{\mathrm{i}}+\sum_{i=1}^{n} \mathrm{k}_{\mathrm{i}} \Delta \rho_{\mathrm{i}}
$$

Para seguir adelante conviene recordar que el crecimiento de la productividad total de los factores es aquella parte del crecimiento de la economía que no es explicada por la acumulación de los factores productivos, esto es, capital y trabajo. Reordenando términos en la expresión anterior, se obtiene una nueva igualdad que se expresa a continuación:

$$
\sum_{i=1}^{\mathrm{n}} \mathrm{p}_{\mathrm{i}} \Delta \mathrm{y}_{\mathrm{i}}-\sum_{i=1}^{n} \mathrm{w}_{\mathrm{i}} \Delta \mathrm{l}_{\mathrm{i}}-\sum_{\mathrm{i}=1}^{n} \rho_{\mathrm{i}} \Delta \mathrm{k}_{\mathrm{i}}=R=\sum_{i=1}^{n} \mathrm{l}_{\mathrm{i}} \Delta \mathrm{w}_{\mathrm{i}}+\sum_{i=1}^{\mathrm{n}} \mathrm{k}_{\mathrm{i}} \Delta \rho_{\mathrm{i}}-\sum_{i=1}^{n} \mathrm{y}_{\mathrm{i}} \Delta \mathrm{p}_{\mathrm{i}}
$$

La expresión del lado izquierdo corresponde, ahora a nivel descentralizado, a lo que habitualmente se estima como el residuo (R) no explicado por la acumulación de los factores o más comúnmente como productividad total de los factores. Si nos detenemos en la expresión de la derecha podremos comprobar que la única forma de que $\mathrm{R}$ sea positivo, es decir que exista crecimiento de la productividad, es que haya ganancias en eficiencia. Por ejemplo, ante un aumento equivalente en los precios de los factores productivos habrá un valor positivo de $\mathrm{R}$ si el precio del producto aumenta en una menor proporción. Para que ello sea posible y tenga sentido tendrá que ocurrir alguna reasignación de esos recursos productivos que permite "financiar" esa ganancia en eficiencia. En la medida que existan barreras a esa reasignación esas ganancias no podrán concretarse y, por tanto, tampoco podrá materializarse un crecimiento de la productividad total de los factores, dañando el crecimiento de la economía.

Este crecimiento en la productividad es fundamental, además, por su impacto en la acumulación de capital. Para entenderlo piénsese en el modelo tradicional de crecimiento de Solow (1956). Si ocurre por una vez un cambio tecnológico neutral a la Hicks —esto es, un aumento de eficiencia que aumenta el producto en igual proporción para todas las combinaciones posibles de insumos- el stock de capital aumentará también por una vez y el producto será más alto como consecuencia del aumento en la 
productividad y la acumulación de capital. Si se intentase explicar ex post este aumento en el producto a través de un ejercicio contable de crecimiento como el que subyace al lado izquierdo de la ecuación (4) atribuiríamos una parte del mismo a la acumulación de capital, pero ciertamente ésta no se habría concretado de no ocurrir ese cambio tecnológico. Este planteamiento teórico parece tener asidero empírico. Por ejemplo, Grossman y Helpman (1994) demuestran que las tasas de crecimiento de la productividad difieren entre países y que éstas están correlacionadas con la tasa de inversión en una muestra de 22 países en el período 1970-88. Un análisis del sector manufacturero chileno realizado por Beyer (2001) sugiere también que los crecimientos en la productividad incentivan nuevas inversiones y contrataciones adicionales (la medición es empleo ajustado por capital humano).

El positivo ciclo de crecimiento de la economía chilena entre 1985 y 1997 posiblemente estuvo marcado por un círculo virtuoso de alto crecimiento en la productividad, documentado en diversos estudios, que alimentó la acumulación de capital. Hasta ahora la relación de lo que hemos planteado con la desigualdad no es evidente, pero en la sección dos intentaremos establecer el nexo. En términos simples, el patrón de desarrollo de la economía chilena (en gran medida de las economías latinoamericanas), como consecuencia de la abundancia relativa de recursos naturales, puede pasar por una etapa de alta desigualdad y mantenerse en esa situación durante un período prolongado si no va acompañado de una acumulación rápida de capital humano. Si ello no ocurre se frena el paso a niveles mayores de desarrollo a través de dos vías potenciales. Por una parte, se frena la posibilidad de pasar a una etapa superior de desarrollo que involucra la producción de bienes más sofisticados de mayor valor agregado y, en segundo lugar, se frena ese círculo virtuoso de alto crecimiento en la productividad - hay tecnologías que no pueden absorberse por falta de capital humano- y acumulaciones posteriores de capital que aceleran el crecimiento. En esas circunstancias se mantiene también un alto premio al capital humano y a los dueños de los recursos naturales y bajos salarios para el trabajo poco calificado. Esto se aborda con más precisión en la sección 2. En la sección tres se hacen algunas reflexiones muy breves sobre el desarrollo chileno de las últimas décadas y las dificultades que existen, desde el punto de vista de los modelos de crecimiento, para explicar el insuficiente nivel de ingreso per cápita del país. La sección cuatro aborda algunos desafíos en educación teniendo en cuenta que se debe dar un gran impulso a la creación de capital humano. 


\section{Desarrollo y desigualdad: una visión simplificada}

Necesitamos un marco mínimo indispensable para visualizar las interacciones que ocurren entre desigualdad y desarrollo y el papel que cumple el capital humano en este proceso. Para avanzar en la definición de este marco se utiliza la Figura $\mathrm{N}^{\circ} 1$ que sigue muy de cerca a Leamer (1987) y Leamer et al. (1999). La interpretación de la figura puede parecer algo compleja pero no lo es tanto una vez que se aprecian los elementos esenciales de ella.

FIGURA $N^{\circ}$ 1: $\quad$ SIMULACIÓN DE POSIBLES ESTRUCTURAS PRODUCTIVAS DE LA ECONOMÍA

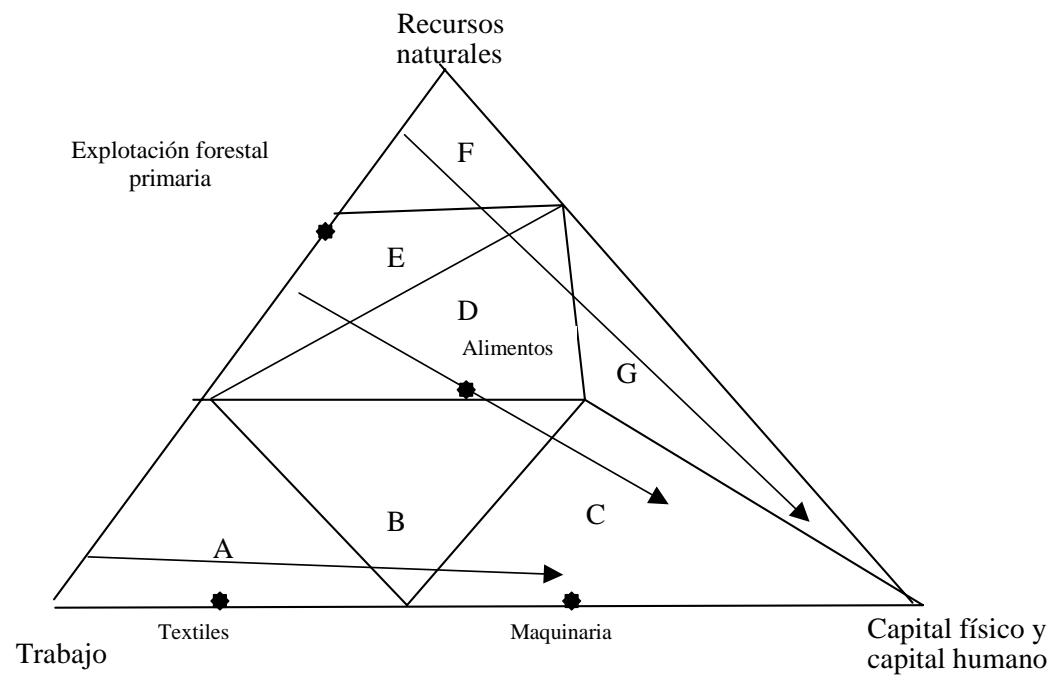

Los vértices representan tres factores de producción: trabajo, recursos naturales (ampliamente definidos) y capital (tanto humano como físi$\mathrm{co}^{3}$ ). Las disponibilidades de estos tres factores productivos en un determinado país y la intensidad de uso de los mismos se representan en esta figura por un punto. La acumulación de un factor productivo (digamos capital), manteniendo fijos los otros factores productivos, significa un desplazamiento del punto de dotaciones de un país hacia el vértice respectivo (del capital). Esto significa que sobre una línea que pase por el vértice del

${ }^{3}$ Es extensa la literatura que sugiere un alto grado de complementariedad entre ambos tipos de capital. Véase, por ejemplo, Goldin y Katz (1998). 
capital, la relación entre recursos naturales y trabajo se mantiene constante. Esto permite medir en los bordes del triángulo las razones entre los distintos factores productivos. Así a lo largo del borde inferior se representa la relación capital-trabajo. Se desprende de la figura que, por ejemplo, la producción de maquinaria necesita relativamente más capital que la de textiles. Sobre el borde izquierdo se representa la razón entre recursos naturales y trabajo y en el borde derecho la relación entre capital y recursos naturales. El desarrollo consiste, a grandes rasgos, en un proceso de acumulación de capital que lleva a los países a desplazarse desde el borde izquierdo en dirección al vértice del capital.

Las áreas geométricas definidas por las letras A ... F representan conos productivos. El cono productivo en el que se encuentre un país en cada momento de su desarrollo se determina por su dotación de factores, esto es: trabajo, recursos naturales y capital (definido ampliamente como capital físico y humano aprovechando la creciente literatura que evidencia complementariedad entre ambos). En los inicios se puede asumir que la partida es sobre el borde izquierdo de la figura en función de sus dotaciones iniciales de trabajo y recursos naturales. Un país como Corea, por ejemplo, con abundante trabajo y pocos recursos naturales estará posicionado muy cerca del vértice del trabajo. Un país como Australia, de abundantes recursos naturales y poco trabajo, partirá su desarrollo más cerca del vértice de recursos naturales. En cada uno de estos conos productivos se satisface el teorema de la igualación de los precios de los factores productivos porque los países que lo integran tienen similares dotaciones de factores y, posiblemente, acceso a las mismas tecnologías. En estos conos, como el mix de producción está fijo, los cambios en la oferta de los factores no afectan sus precios.

En general, un país que es abundante en trabajo y recursos naturales producirá más hacia la izquierda de la Figura $\mathrm{N}^{\mathrm{o}} 1$ (digamos en el punto que une a las áreas geométricas $\mathrm{A}, \mathrm{B}$ y D). Un país que es relativamente abundante en capital, que en este esquema es desarrollado, estará posicionado más a la derecha en esta figura (digamos en los conos productivos $\mathrm{G}$ o C). Mientras más cerca está un país de alguno de los vértices más abundante es ese recurso y, por tanto, menor el precio relativo del factor productivo que aparece en el vértice. Así en A, el salario que obtiene el trabajo es menor que aquel que obtendría en D. En cualquiera de esos conos el premio al capital es elevado (estamos muy alejados del vértice que representa al capital) y, por tanto, cabe esperar un nivel de desigualdad relativamente alto. 
Pensemos en este contexto en el desarrollo chileno. Parece razonable pensar que en sus inicios este parte en el cono E amparado, básicamente, en recursos naturales y trabajo. La abundancia relativa de recursos naturales permite sostener salarios relativamente altos para el trabajo no calificado sobre la base de, por ejemplo, una agricultura primaria, explotación bruta de árboles (tala indiscriminada de bosques) y una minería muy rudimentaria ${ }^{4}$.

El paso siguiente es poner algo de capital en este proceso de desarrollo. La acumulación de capital nos desplaza hacia una industria basada en los recursos naturales que es más intensiva en capital y produce a gran escala, economizando en trabajo poco calificado que gradualmente es reemplazado por trabajo más calificado. En términos de la Figura $\mathrm{N}^{\circ} 1$ esto significa desplazarse desde $\mathrm{E}$ a $\mathrm{D}$. Este paso mantiene un alto premio para los dueños del capital físico y humano y eleva los retornos para los dueños de los recursos naturales, al mismo tiempo que hace caer relativamente los salarios de los trabajadores poco capacitados (el patrón de desarrollo nos empuja más cerca del vértice del trabajo) ${ }^{5}$. Esta etapa es ciertamente la de mayor desigualdad relativa y coincide con el hecho de que, en el margen, algunas industrias deben competir con las de países que tienen salarios relativos muy bajos (países que están en el cono productivo B). Para ser competitivos no pueden pagar salarios muy altos a no ser que la economía sea mucho más productiva, pero no es evidente que eso pueda lograrse con facilidad.

Esta realidad se puede contrastar con los patrones de desarrollo de países de pocos recursos naturales que parten en un cono productivo como A. En estos casos no hay recursos naturales que remunerar y los salarios son relativamente muy bajos. Inicialmente los premios al capital son relativamente altos, pero el proceso de desarrollo supone una acumulación gradual de capital físico y humano y, como consecuencia de ello, un alza desde el principio de los salarios relativos de los trabajadores poco calificados y reducción gradual (a medida que nos acercamos al vértice del capital) de los premios al capital. Es, por consiguiente, un patrón de desarrollo que no supone grandes niveles de desigualdad. Ahí están los casos de Corea, Japón, Taiwán y Hong Kong para corroborar este fenómeno. Han

${ }^{4}$ Es importante tener en cuenta que cuando hablamos de salarios relativamente altos para el trabajo no calificado estamos haciéndolo en el contexto del bajo nivel de desarrollo que tiene el país en esa etapa. En ese sentido pueden ser salarios que apenas o ni siquiera son de subsistencia.

${ }^{5}$ Esto no significa necesariamente una caída de sus salarios reales aunque sí un deterioro relativo. 
tenido un desarrollo acelerado manteniendo un bajo nivel de desigualdad. Pero, ¿tiene este análisis teórico un sustento empírico mayor que estos casos anecdóticos? En Leamer et al. (1999) hay interesante evidencia que establece persuasivas correlaciones entre desigualdad y estructura productiva de los países.

Siempre cabe la pregunta de si no es posible cambiar nuestro patrón de desarrollo. Esto es equivalente a preguntarse si podemos alterar nuestras dotaciones de recursos productivos. Podríamos intentar aislarnos del mundo, pero la experiencia sugiere que esa opción tiene un costo enorme en términos de crecimiento y no escapa a las presiones que sobre la distribución de los ingresos tiene la realidad productiva del país. El camino más razonable es intentar salir rápidamente del cono productivo D y desplazarnos a uno como C. Ahí tenemos una economía muy distinta que es compatible con menores premios al capital y mayores salarios relativos para el trabajo no calificado. Los recursos naturales ya no se utilizan tan intensivamente y pierden importancia a estas alturas del desarrollo. Se genera un cuadro, entonces, donde los niveles de desigualdad se han reducido. Además, por haber más capital disponible es una situación de mayor ingreso per cápita. En este sentido si logramos superar el actual estado de las cosas es altamente probable que comencemos a observar reducciones importantes en los actuales niveles de desigualdad.

Sin embargo, y aquí nos enfrentamos a una barrera importante, requerimos un buen nivel de capital humano para avanzar en esta dirección. Sin un buen sistema educacional difícilmente se podrá lograr dicho propósito. Una fuerza de trabajo calificada atraerá nuevas tecnologías y más capital. No es casualidad que países como Suecia y Finlandia, que hasta bien avanzado el siglo 20 eran principalmente exportadores de materias primas, exhiban desarrollos tecnológicos significativos y al mismo tiempo obtengan excelentes resultados en diversas pruebas internacionales de educación. Parte del problema de Chile en esta etapa es que hasta aquí no ha sido realmente imprescindible contar con elevados niveles de capital humano. Es ahora donde comienza a importar y es difícil reformular el marco institucional para acoger esos desafíos. La situación es muy distinta de la observada, por ejemplo, en los países asiáticos antes mencionados. En esos casos la necesidad de capital humano se hizo evidente desde los inicios del proceso de desarrollo. Debe haber habido, por consiguiente, una preocupación muy temprana por alcanzar altos estándares educativos.

Una muestra de la escasez de capital humano en el país queda reflejada en el Gráfico $\mathrm{N}^{\circ} 1$ que presenta la evolución de los retornos 
marginales de un año de educación para distintos niveles educativos ${ }^{6}$. Se ve con claridad que ha aumentado en forma significativa el retorno de la educación superior, especialmente en las últimas dos décadas mientras que los retornos a la educación primaria y secundaria han caído en forma dramática. Es difícil entender esta evolución en los premios a distintos tipos de educación, más todavía cuando durante el período analizado este fenómeno ha ido acompañado de un aumento significativo en la oferta relativa de ocupados con estudios terciarios.

GRÁFICO N ${ }^{\circ}$ 1: RETORNOS DE DISTINTOS TIPOS DE EDUCACIÓN Y OFERTA RELATIVA DE GRADUADOS UNIVERSITARIOS (GRAN SANTIAGO)

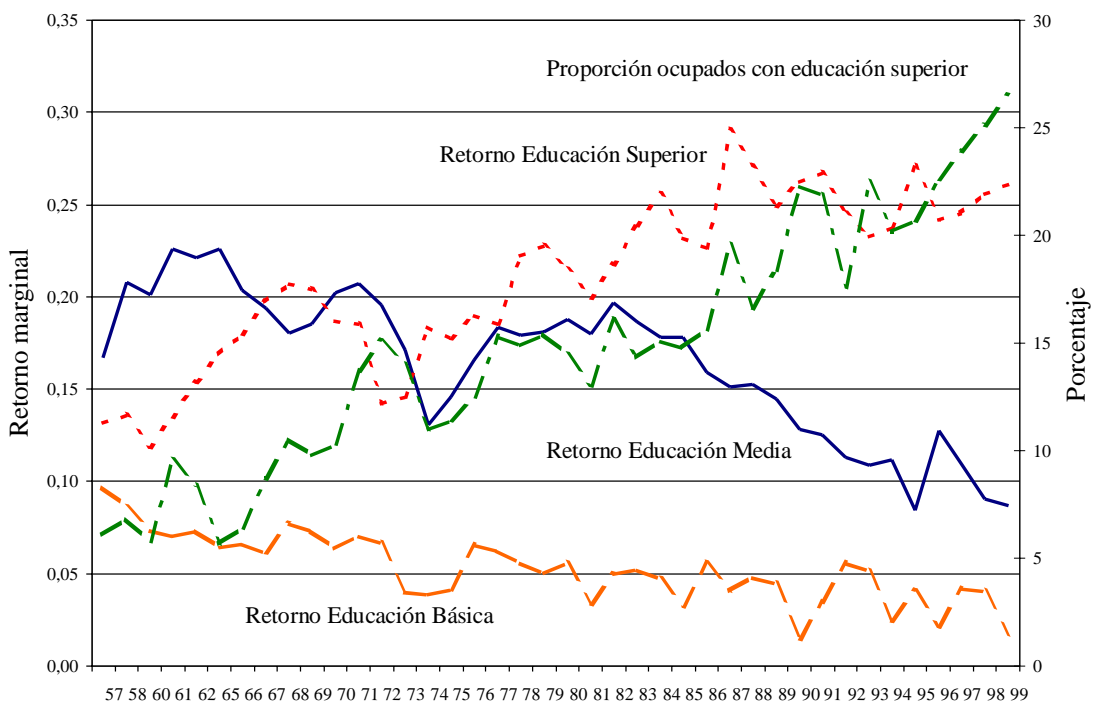

Año

Fuente: Elaboración propia en base a las encuestas de empleo de la Universidad de Chile, junio de cada año.

Estos números son compatibles con la idea de un desplazamiento en el proceso de desarrollo que eleva el precio relativo del capital y reduce los salarios relativos de los trabajadores menos calificados. Para salir de este estado de cosas es imprescindible acumular más capital humano. Los altos

${ }^{6}$ Se estima un modelo de capital humano a la Mincer que acepta que el retorno de un año adicional de educación es distinto en la básica, que en la media o la universitaria. Mayores detalles se pueden encontrar en Beyer (2000). 
premios a la educación terciaria son desde luego un gran incentivo para producir descentralizadamente las inversiones requeridas. De hecho, en Chile se han observado importantes aumentos de cobertura, aunque permanecen obstáculos que tienen que ver con la falta de un sistema adecuado de financiamiento de la educación superior que signifiquen impulsos adicionales a la formación de capital humano. En términos prácticos estas cifras sugieren que el ritmo al que se está formando capital humano es insuficiente para absorber la demanda por el mismo. Este cuadro es compatible, además, con el resultado del teorema de la igualación de los precios de los factores que defiende la idea de que cambios en la oferta relativa de alguno de los factores no afectará el precio de los mismos.

Por cierto, hay explicaciones alternativas para estos altos premios a la educación superior. Éstas parten de la observación de que el alza relativa en el premio a esta modalidad educativa ha ocurrido en un número suficientemente grande de países como para intentar una explicación de carácter más general. Dos parecen ser los principales candidatos: el fuerte ingreso de países de poco desarrollo y bajos salarios a un escenario de intercambio comercial creciente y cambios tecnológicos sesgados en pro de trabajadores calificados. La evidencia no es del todo convincente, especialmente en el caso de aquella que descansa sobre el intercambio comercial. Borjas et al. (1997) han estimado que este hecho podría explicar no más del 20 por ciento del alza en el premio salarial de los trabajadores más calificados en Estados Unidos, el país donde el premio relativo para los graduados de la educación superior ha subido más respecto de otros países industrializados. La segunda hipótesis parece tener mayor asidero. Si sube el precio relativo de los trabajadores más calificados cabría esperar que las empresas realizaran en algún grado una sustitución de estos trabajadores ${ }^{7}$. Sin embargo, como demuestran Berman et al. (1998) lo que se observa, en países con instituciones del mercado laboral muy distintas, es más bien una mayor contratación relativa de trabajadores calificados y que la proporción más grande de este cambio proviene de cambios al interior de las industrias antes que entre industrias, lo que sugiere un aumento relativamente generalizado de la demanda por trabajadores calificados, que acota de paso la explicación de los flujos comerciales.

Esta tendencia también parece estar presente en Chile. Entre 1979 y 1986, en la industria manufacturera chilena, Pavncik (2003) encuentra que la proporción de empleo calificado subió en un 16,8 por ciento y que el premio a este empleo subió un 10,6 por ciento. Este cambio ocurrió princi-

${ }^{7}$ Existe debate respecto de si se pueden sustituir con efectividad ambos tipos de trabajadores. 
palmente al interior de cada una de las industrias más que entre industrias, corroborando los antecedentes internacionales informados en Berman et al. En efecto, un 89 por ciento en el desplazamiento hacia trabajadores calificados se explicaría en esos años por los cambios ocurridos al interior de cada industria. Sin embargo, este estudio no encuentra que este desplazamiento hacia trabajadores más calificados tenga su origen en cambios tecnológicos. Las demandas por trabajadores más calificados parecen tener su origen en incrementos en la inversión de las plantas analizadas. Por cierto, no se puede descartar que detrás de ambos fenómenos, aumentos en empleo calificado e inversión, haya una causa común que es un aumento en la productividad total de los factores. Para un período distinto, 19861996, Beyer (2002) estima crecimiento en la productividad total de los factores a nivel de plantas y demuestra que estos crecimientos anticipan aumentos en la inversión y en capital humano ${ }^{8}$. Para alimentar el crecimiento, entonces, es indispensable aumentar la productividad, pero también tener disponible el capital humano para sostener ese proceso y, simultáneamente, avanzar hacia mayores niveles de igualdad.

\section{Algunas consideraciones sobre el desempeño económico de Chile}

Planteábamos al comienzo que el mundo se ha hecho más desigual en los últimos 200 años. Ese no es el resultado de mayores desigualdades al interior de los países sino que el resultado de diferencias más grandes en los ingresos per cápita entre países. La desigualdad intrapaíses se habría reducido hacia 1950 y luego se habría mantenido relativamente constante con una pequeña subida en los 80 . En cambio la desigualdad entre países prácticamente no ha dejado de aumentar desde 1820. Según Bourguignon y Morrison (2002), entre 1820 y 1992 el ingreso medio de los habitantes del mundo se multiplicó por 7,6. Sin embargo, el del decil superior lo hizo en 10 veces mientras que el del quintil inferior lo hizo sólo en 3 veces. Con todo, la pobreza extrema habría caído desde un 84 por ciento en 1820 a un 24 por ciento en 1992.

Esta tendencia hacia una mayor desigualdad en el ingreso per cápita entre países queda de manifiesto en el Gráfico $\mathrm{N}^{\circ} 2$ que ordena a los países de menor a mayor ingreso per cápita. Se observa en este lapso de cuatro

${ }^{8}$ En este estudio se utiliza una medida de empleo expresada en términos de unidades básicas de capital humano. Por tanto, los cambios en la contratación se miden en términos de incrementos o decrecimientos en la contratación de esas unidades de capital humano. 
GRÁFICO No 2: $\quad$ INGRESO PER CÁPITA DE PAÍSES EN 1960 Y 2000 ORDENADOS DE MENOR A MAYOR

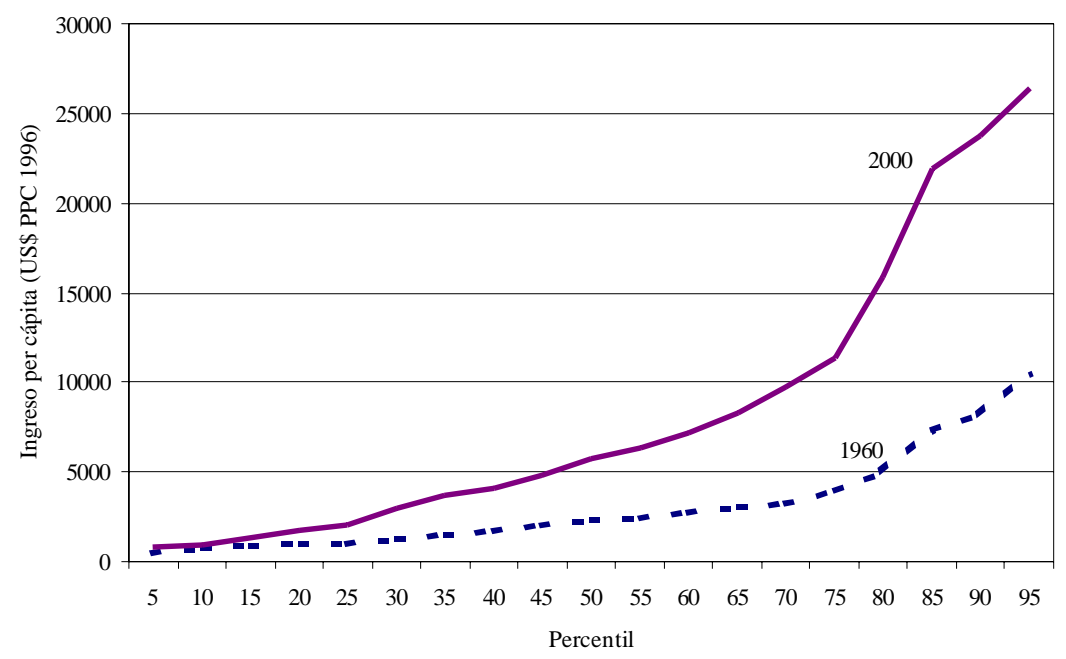

Fuente: Elaboración propia sobre la base de World Penn Tables v. 6.1

décadas un aumento en la brecha entre países ricos y pobres. Por cierto, hay países que logran avanzar pero otros se estancan, y queda la sensación que en el futuro podría haber dos grupos de países claramente diferenciados: los ricos y los pobres. Esa posibilidad ciertamente llama a la reflexión e invita a estar permanentemente revisando la pregunta que intentaba responder hace más de 200 años Adam Smith.

Viendo este heterogéneo panorama de crecimiento de las economías, parece pertinente indagar por el desempeño relativo de la economía chilena en las últimas décadas. En el Gráfico $\mathrm{N}^{\mathrm{o}} 3$ se estudia si Chile y, en general, las economías latinoamericanas han cerrado la brecha, en términos de ingreso per cápita, respecto de Estados Unidos, o la han aumentado. Este país como un referente central de las economías más ricas. El panorama no es demasiado alentador. Con la excepción de Brasil, que ha acortado distancias con Estados Unidos, los demás países o bien han mantenido las distancias relativas —el caso de Chile y México- o han retrocedido, en algunos casos en forma dramática como Venezuela.

El Gráfico $\mathrm{N}^{\mathrm{o}} 4$ divide este medio siglo en dos subperíodos de igual duración. Se ve con claridad que para el caso de Chile ambos períodos suponen un desempeño muy distinto. En particular, el segundo subperíodo marca un claro contraste con las economías latinoamericanas. Es este des- 
GRÁFICO N ${ }^{\circ}$ 3: ¿CONVERGENCIA EN INGRESO PER CÁPITA RESPECTO DE ESTADOS UNIDOS? (CAMBIOS EN BRECHA: PUNTOS PORCENTUALES)

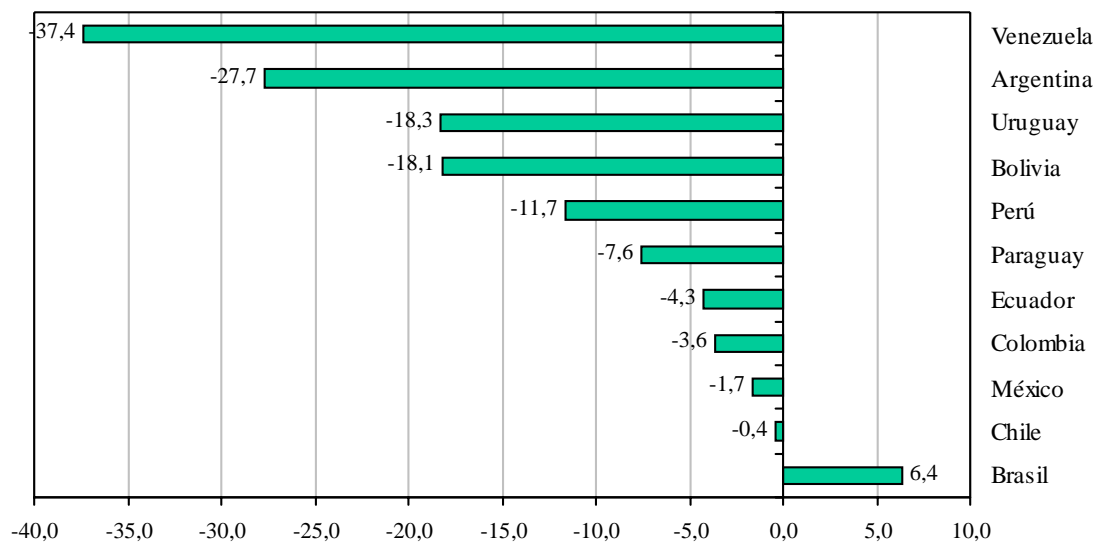

Fuente: Elaboración propia sobre la base de World Penn Tables V. 6.1.

empeño el que permite estar optimista respecto de las potencialidades de la economía chilena. Los últimos 25 años estuvieron marcados por una apertura comercial mayúscula y una serie de reformas que cambiaron drásticamente la calidad de las políticas económicas. La recuperación de la democracia en la última década le dio un impulso definitivo al nuevo marco económico, otorgándole no sólo legitimidad sino que también profundizándolo y perfeccionándolo en muchos aspectos.

El acortamiento de la brecha en el ingreso per cápita respecto de Estados Unidos es el resultado, como se aprecia en el Gráfico $\mathrm{N}^{\circ} 5$, de una aceleración en el crecimiento de la economía.

El Gráfico $N^{\circ} 6$ sugiere que esta aclaración en el crecimiento tiene como causa principal fuertes aumentos en la productividad ${ }^{9}$. Hasta un 40 por ciento de ese crecimiento podría ser explicado por esta variable y habida cuenta de la influencia que parece ejercer el crecimiento de la productividad sobre la acumulación de factores, esa magnitud puede estar subestimada.

El Gráfico $N^{\circ} 6$ deja en evidencia, además, que durante el proceso de fuerte crecimiento de la productividad la razón capital-producto retroce-

${ }^{9}$ Una explicación de la forma de cálculo de los niveles de productividad y de la relación capital producto que aparecen en este gráfico se encuentra en Beyer (2003). 
1950-1975

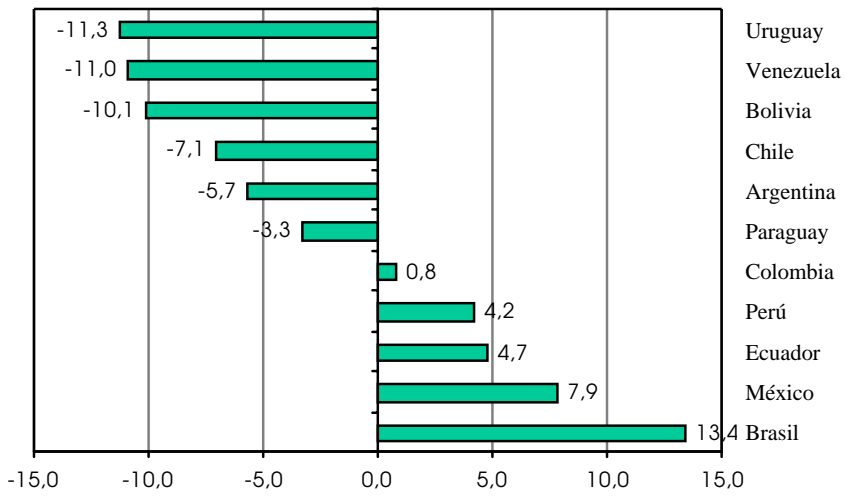

$1975-2000$

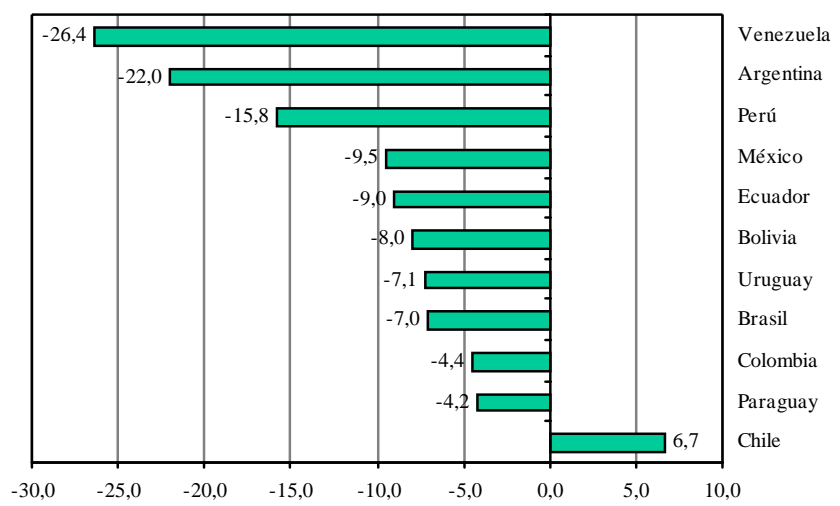

Fuente: Elaboración propia sobre la base de World Penn Tables V. 6.1.

de, avalando la idea de que este impulso se basa, al menos parcialmente, en un uso más eficiente de los factores disponibles. Para avanzar un poco más en el reconocimiento de la productividad como un factor central en el crecimiento del ingreso per cápita conviene plantear un modelo un poco más formal de crecimiento. Para estos efectos piénsese en una función de producción para el país i en el momento t como la que sigue:

$$
\mathrm{Y}_{\mathrm{it}}=K_{i t}^{\alpha}\left(H_{i t} A_{i t}\right)^{1-\alpha}
$$


GRÁFICO N ${ }^{\circ}$ 5: $\quad$ LA EVOLUCIÓN DEL INGRESO PER CÁPITA EN LAS ÚLTIMAS DÉCADAS (Dólares de 1996 ajustados por el poder de compra)

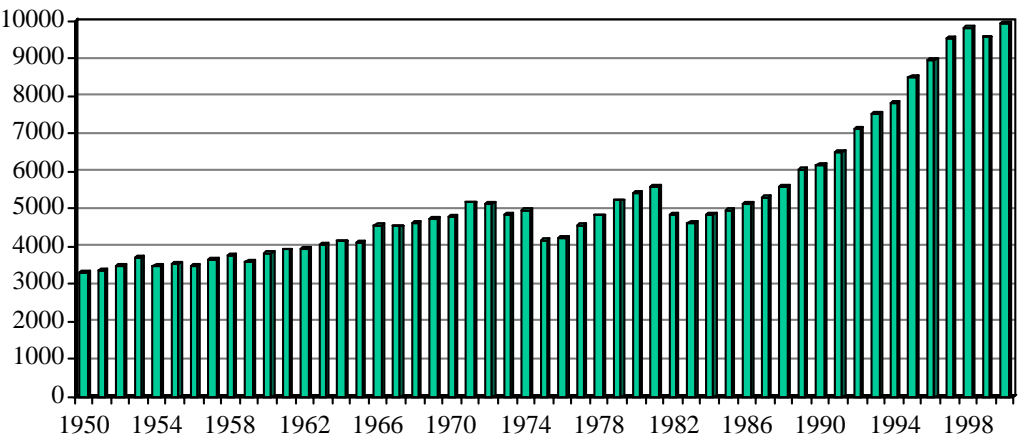

Fuente: Elaboración propia sobre la base de World Penn Tables v. 6.1.

\section{GRÁFICO N ${ }^{\circ}$ 6: $\quad$ LA IMPORTANCIA DE LA PRODUCTIVIDAD EN EL CRECIMIENTO RECIENTE DE CHILE}

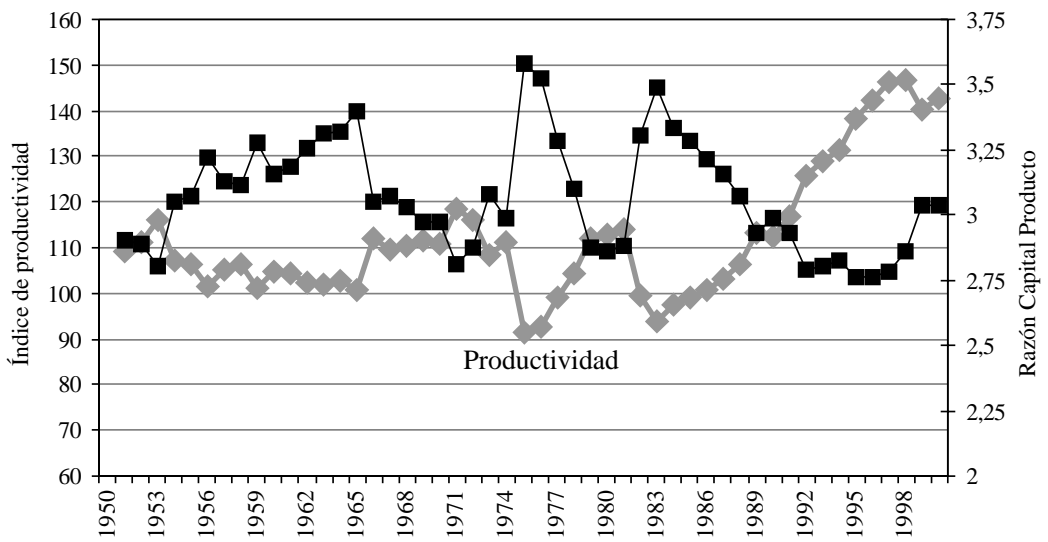

Fuente: Elaboración propia sobre la base de World Penn Tables v. 6.1 y Beyer (2003)

donde $\mathrm{Y}_{\mathrm{it}}$ es el nivel de producto, $\mathrm{K}_{\mathrm{it}}$ es el stock de capital, $\mathrm{H}_{\mathrm{it}}$ es el stock de capital humano y $\mathrm{A}_{\mathrm{it}}$ representa una tecnología que eleva el aporte productivo del trabajo y que crece exógenamente a una tasa $\mathrm{g}$. $\mathrm{A}_{\mathrm{it}}$ podría representarse en la práctica como $\mathrm{A}_{\mathrm{oi}}(1+\mathrm{g})^{\mathrm{t}}$. En este modelo sencillo $\alpha$ es la participación del capital en el producto. Para hacerlo simple se puede suponer que: 


$$
\mathrm{H}_{\mathrm{it}}=\mathrm{L}_{\mathrm{it}}{ }^{*} \mathrm{~h}_{\mathrm{it}}
$$

donde $\mathrm{L}$ representa trabajo bruto y $\mathrm{h}$ es una expresión que captura las habilidades promedios de esos trabajadores. Blis and Klenow (2000) sugirieron la siguiente expresión:

$$
\mathrm{h}_{\mathrm{it}}=e^{\phi\left(s_{i t}\right)}
$$

donde $s_{\text {it }}$ denota la escolaridad promedio de la población económicamente activa. De manera más concreta, estos autores sugieren la siguiente forma funcional:

$$
\phi(s)=\frac{\theta}{1-\psi} s^{1-\psi}
$$

con valores $\theta=0.32$ y $\psi=0.58$. Hecho este planteo general, se puede intentar comprender las implicancias para la economía chilena de este modelo. Expresando la primera de estas ecuaciones en términos de unidades de producto por trabajador, tenemos:

$$
\mathrm{y}_{\mathrm{it}}=k_{i t}^{\alpha}\left(h_{i t} A_{i t}\right)^{1-\alpha} \text {. }
$$

Partiendo de la expresión anterior se puede tratar de entender las diferencias del producto por trabajador entre países. En principio, dados los supuestos iniciales, $A_{i t}$ no debería exhibir grandes diferencias entre países. Sí hay diferencias en k y h. Usando los antecedentes recopilados por Summer y Heston en las World Penn Tables (específicamente la versión 6.1) y utilizando el método de inventarios perpetuos se pueden construir las series de stock de capital por trabajador para un grupo importante de países. Por otra parte, la base de datos compilada por Barro y Lee contiene información sobre la escolaridad promedio de la población de 15 años y más (y 25 años y más) para una muestra de más de 100 países. Utilizando estos datos se puede intentar predecir las diferencias de ingreso por trabajador entre países ${ }^{10}$. Si se hace ese ejercicio para Chile y Estados

${ }^{10}$ Hay una discusión mucho más detallada aunque más técnica en Beyer (2003). Habitualmente esta comparación se hace en el estado estacionario, es decir en aquel momento en que el producto por trabajador crece solamente a la tasa a la que se expande exógenamente la tecnología. Se puede demostrar que, dadas las formas funcionales aquí expuestas, en el estado estacionario el ingreso por trabajador se representa como

$$
\mathrm{y}^{*}(\mathrm{t})=(\mathrm{s} /(\mathrm{n}+\delta+\mathrm{g}))^{\frac{a}{1-\alpha}} \mathrm{hA}(\mathrm{t}) .
$$

Esta particular forma funcional obedece a que se asume que la escolaridad es constante y determinada exógenamente. En el estado estacionario, entonces, el nivel de producto dependería de la tasa de ahorro de los países, de su nivel de capital humano y de su nivel de productividad, que en el modelo, está implícito, es similar entre países. 
Unidos, por ejemplo, y se asume un valor de $\alpha$ de entre 0,33 y 0,45 (compatibles con la participación del capital en el producto una vez que se da cuenta del trabajo informal o por cuenta propia que incorrectamente suele imputarse como ingreso del capital), uno arriba a la conclusión de que en el año 2000 el producto por trabajador debería haber sido en nuestro socio comercial entre un 62 y un 69 por ciento más alto que en Chile. Sin embargo, los datos efectivos para ese año indicaban que el producto por trabajador era un 157 por ciento más alto en el país del norte que en nuestro país (todos los datos pertinentes están en dólares ajustados por la paridad del poder de compra).

Probablemente las diferencias predichas en el producto por trabajador aumentarían si utilizáramos un mejor indicador de capital humano que esta forma funcional asociada a la escolaridad promedio de la población. Las diferencias de capital humano entre ambos países posiblemente son mucho mayores de las que sugieren las diferencias en escolaridad. Aun así las diferencias efectivas seguirían siendo mucho mayores que las predichas. Con todo, cabe hacer notar que dado los valores realistas de $\alpha$, inferiores a 0.5 , las diferencias en el stock de capital humano aportarían relativamente más a explicar las diferencias en el ingreso per cápita entre países que las diferencias en el stock de capital. El principal factor detrás de este yerro en la predicción de las diferencias en los ingresos per cápita parece estar en la "ingenuidad teórica" de suponer que A(t) es aproximadamente similar entre países, lo que equivale a argumentar que el progreso tecnológico (o si se quiere el crecimiento de la productividad) es efectivamente exógeno y que como consecuencia de ello todos los países expanden su frontera de producción al mismo ritmo, esto es, que las diferencias en el ingreso per cápita serían finalmente sólo el resultado de diferencias en los stocks de capital humano y físico. No era eso lo que sugería el Gráfico $\mathrm{N}^{\mathrm{o}} 6$ que mostraba una evolución cambiante de la productividad en las últimas décadas. El crecimiento de esta variable difiere, además, significativamente de un país a otro. Hay una larga lista de factores que pueden influir en este dispar desempeño, algunos de ellos difíciles de sustentar empíricamente, aunque pocos dudan que las políticas y las instituciones juegan, al respecto, un papel crucial. El desafío para un país como el nuestro es asegurarse que su inversión en educación se traduzca efectivamente en mayores niveles de capital humano y que sus instituciones y políticas faciliten el crecimiento de la productividad y no le impongan costosas barreras. 


\section{La necesidad de un marco institucional distinto en educación}

\subsection{Consideraciones preliminares}

En diversos pasajes de este artículo ha ido quedando de manifiesto el papel central del capital humano en el progreso del país y la contribución que éste puede hacer a reducir las desigualdades de ingreso del país. Los avances en ambas dimensiones parecen, además, estar mucho más interrelacionados de lo que podría pensarse a primera vista. Para elevar nuestros niveles de capital humano es indispensable poner nuestra educación en un nivel sustancialmente superior al actual. Sugerimos que, en parte, los decepcionantes resultados de nuestro sistema educacional obedecen a que hasta ahora no hemos requerido de este factor productivo para pavimentar nuestro crecimiento, e incluso hemos dejado entrever que, dada nuestra dotación de recursos, el escenario de alta desigualdad era en alguna medida inevitable. Por supuesto éste es un problema de grados y mejores políticas educativas en el pasado habrían ayudado a amortiguar estas inercias desiguales. Pero en esta etapa de desarrollo se abre una oportunidad para progresar reduciendo desigualdades y ahora la falta de capital humano puede ser una barrera para avanzar en esta dimensión. Por ello, más allá de las distintas demandas que se le planteen al sistema educacional, deben redoblarse los esfuerzos para que nuestro sistema educacional alcance estándares mínimos de rendimiento académico. Las diversas pruebas internacionales, que son un primer buen estándar para nuestro sistema educacional, revelan que Chile está en un nivel que no se condice con nuestros actuales niveles de desarrollo económico y social y tampoco con los recursos públicos y privados que se destinan a educación.

La insatisfacción con la educación no sólo es un problema nacional y debates similares al nuestro se repiten en los más diversos países. Hay reparos tanto por su aporte al crecimiento económico como por su contribución a reducir las desigualdades. Expertos como Pritchett han llegado a preguntarse “¿Hacia dónde se ha ido toda la educación?”"1. Numerosos países han experimentado significativos aumentos en sus niveles educacionales sino que ello se haya traducido en cambios apreciables en la tasa de crecimiento económico o en la desigualdad. Hay dos caminos posibles para salir de esta aparente contradicción. La primera y más obvia es que no importa tanto la cantidad como la calidad. Aumentos en el número de años de educación, que muchas veces se logra elevando los años de educación obligatoria, no necesariamente significan elevar las habilidades de las per-

${ }^{11}$ Véase Pritchett (1997). 
sonas que reciben esa educación. Como son esas habilidades las que importan para el crecimiento económico, la conclusión parece obvia: más años de educación no necesariamente significan más crecimiento económico. Estudios que han tratado de capturar, todavía muy imperfectamente, la calidad de la educación en sus estimaciones parecen sugerir que ahí hay un factor que tiene una incidencia importante, al menos, en el crecimiento económico $^{12}$.

Un segundo camino para enfrentar la evidencia que sugiere que no hay relación entre crecimiento y educación es constatar que una buena educación es una condición necesaria pero no suficiente para que los países prosperen. Si es más rentable hacer lobby, si los precios están distorsionados, si los derechos de propiedad no están bien protegidos, en fin, si los proyectos que generan riqueza no son rentables, difícilmente llegarán las tecnologías y las inversiones necesarias para aprovechar a la población educada. Sin incentivos e instituciones adecuadas una buena educación no rendirá los frutos esperados ${ }^{13}$.

Por último, y como tratamos de sostener en la sección dos, la relación entre todas las variables económicas es compleja y hay patrones bien trazados que subyacen a todo proceso de desarrollo. La clave es ir despejando las barreras que pueden frenar ese proceso. Con todo, tampoco hay que exagerar los argumentos de Pritchett. Hay países que han avanzado aceleradamente en desarrollo económico sustentados sobre un buen sistema educacional y con niveles de desigualdad moderados o bajos.

La gran ventaja actual de Chile es que los incentivos para el crecimiento están. Por eso las reformas de la educación que eleven el rendimiento educacional de nuestros estudiantes y permitan que se expandan las habilidades de nuestra fuerza de trabajo deberían tener, en el mediano y largo plazo, un impacto significativo en la capacidad productiva del país y seguramente también en la capacidad de atraer nuevas tecnologías. Por lo demás no parece haber ninguna razón estructural para pensar que nuestros estudiantes puedan obtener resultados similares o superiores a los estudiantes de Tailandia, Túnez o Polonia ${ }^{14}$. Los mediocres resultados son compartidos por todos nuestros estudiantes, incluidos los más aventajados

${ }^{12}$ Por ejemplo, véase Beyer y Vergara (2003). Estos autores sugieren que un mejoramiento en la calidad de la educación que coloque a nuestros alumnos en el rendimiento promedio de una prueba como el TIMSS podría elevar nuestra tasa de crecimiento en 0,7 puntos porcentuales al año.

${ }^{13}$ Un buen análisis de la importancia de incentivos e instituciones en el crecimiento económico se encuentra en Easterly (2001).

${ }^{14}$ Aquí haremos fundamentalmente referencia a los resultados obtenidos por Chile en las pruebas PISA y TIMSS de 2001 y 2003, respectivamente. 
socialmente. No nos debe extrañar, entonces, que Chile coloque a menos de un $1 \%$ del estudiantado en los grupos formado por el $10 \%$ de rendimiento superior en el mundo ${ }^{15}$. Estos resultados, así como los de otros estudios, sugieren que más allá de nuestra realidad económica y social los desafíos en educación son enormes y que se requiere abordarlos con decisión.

Más allá de consideraciones distributivas, los recursos públicos y privados en educación están. En 1990 el gasto público en educación representaba un 2,5\% del PIB y en la actualidad alcanza a un 4,4\% de esa misma variable. El crecimiento relativo del gasto público en educación ha ido acompañado en el mismo período de una duplicación del PIB. Ambos fenómenos —el mayor énfasis en educación y el incremento del PIB- han permitido que los recursos que actualmente se destinan a la educación pública se hayan más que triplicado en pesos respecto de 1990. Si al esfuerzo del sector público se agregan los aproximadamente tres puntos porcentuales del PIB que gastan los privados en educación podemos constatar que nuestro país destina más del 7\% de lo que produce a educar a sus niños y jóvenes. Esta magnitud nos ubica entre los países del mundo que relativamente más gastan en educación ${ }^{16}$. Los aumentos de recursos, sin embargo, no parecen haber venido aparejados con incrementos proporcionales en el "producto educativo", definido ampliamente como cobertura escolar ajustada por calidad de la educación. En otras palabras, la productividad de los recursos dedicados a educación parece haber experimentado un retroceso. El Cuadro $\mathrm{N}^{\circ} 1$ presenta la evolución de dicha productividad.

CUADRO Nㄴ $\quad$ LA PRODUCTIVIDAD DE LA EDUCACIÓN

(Variaciones promedio anuales)

Productividad de la educación

$\begin{array}{rr}1981-85 & 3,0 \% \\ 1986-90 & 2,7 \% \\ 1991-95 & -8,2 \% \\ 1996-00 & -6,7 \%\end{array}$

Fuente: Véase anexo 1.

${ }^{15}$ De nuevo esta afirmación se basa en los resultados que obtiene nuestro país en las pruebas PISA y TIMSS.

${ }^{16}$ Por supuesto la distribución entre gasto público y privado en educación difiere entre países. Chile es de los países que presentan una alta proporción de gasto privado en educación. 
Queda en evidencia que la productividad de los recursos públicos por estudiante ha caído significativamente en los 90. Por supuesto, estos antecedentes deben mirarse con cautela. Las inversiones en educación demoran en surtir efecto. Además, dichas inversiones ocurrieron después de años de una caída significativa del gasto en los 80 , del orden de 25 por ciento real, que de haberse mantenido en los 90 probablemente habría hecho colapsar la educación chilena. En este sentido los aumentos de productividad ocurridos en los 80 probablemente no eran sostenibles en el tiempo y, por tanto, eran más aparentes que efectivos. Con todo, estos números sugieren que resulta imprescindible asegurarse de que los recursos que ya se han allegado a educación y los que estén por venir sean bien gastados. Ciertamente no deberíamos esperar aumentos significativos en la productividad de los recursos pero tampoco caídas de esta magnitud. Además, sería incorrecto evaluar todo proceso educativo tomando como referencia sólo la productividad de los recursos educacionales. Pero tampoco podemos olvidar que siempre existe la alternativa de ir a un equilibrio de bajo gasto y resultados parecidos a los actuales. Por cierto, se podría argumentar que ese equilibrio no ayuda en nada a superar las desigualdades del país. Pero ese argumento es circular. Un equilibrio de alto gasto tampoco contribuirá a estos propósitos si no hay resultados efectivos y mejoras en los aprendizajes. Y, por tanto, no es evidente a primera vista cuál es el equilibrio deseable. Esta discusión se salva si se avanza hacia un marco institucional que asegure que los recursos destinados a educación se gasten mejor que en la actualidad. El actual marco que rige a la educación no ofrece garantías de que ello ocurrirá así porque está en gran medida capturado por los actores educativos.

\subsection{Los déficits en nuestra educación}

Respecto de si los déficits existen o son más bien el resultado de desigualdades pasadas es un debate que tiene muchas aristas. Además, hay indicadores que invitan a lecturas distintas. Si se miran indicadores tradicionales de eficiencia interna - egreso oportuno, tasas de reprobación o egreso total-, o de cobertura, los resultados del sistema educativo nacional sorprenden positivamente. Así, por ejemplo, en los últimos doce años los tiempos de egreso de la educación básica se han reducido, en promedio, en poco más de un año. Las tasas de reprobación en la educación básica han caído de 7,8\% en 1990 a 2,8\% en 2001. En el mismo período la tasa de reprobación en la educación media ha caído desde 12,4 a 5,9\%. Pero esta 
realidad ¿es consecuencia de una mejor educación o de criterios de promoción más laxos? El punto no es menor porque si bien una educación de calidad debería permitir una reducción en las tasas de reprobación el fenómeno puede tener su origen en cambios en las normas de aprobación antes que en el logro de determinados objetivos pedagógicos. De hecho, hemos sido testigos de cómo en el lapso de 30 años las notas promedio de los estudiantes que rinden las pruebas de admisión a las universidades nacionales han subido en una nota entera. Pocos se atreverían a sostener que ello obedece a los avances que ha registrado nuestra educación secundaria.

Por eso es que más allá de las tendencias nacionales que pueden estar afectadas por factores idiosincrásicos, parece razonable poner el peso de la prueba en los resultados que se obtienen a partir de pruebas internacionales. Ese análisis arroja resultados inquietantes. Suficientemente conocidos son los resultados que han obtenido los adultos chilenos en la Prueba Internacional del Adulto Lector: un $82 \%$ de nuestros compatriotas no alcanzaría los niveles necesarios de comprensión lectora que requieren las sociedades modernas actuales para desempeñarse adecuadamente en el mundo del trabajo. Menos destacado es el hecho de que si uno controla por el nivel educacional, no ha habido ningún avance generacional. En efecto, el nivel de comprensión lectora de una persona de 60 años con educación media es equivalente al nivel de comprensión lectora de una persona de 20 años con el mismo tipo de educación. "iQué 20 años no es nada!” dice la canción. Pues en educación tampoco parecen serlo 40. Por lo menos en Chile. La persistencia de los resultados (mediocres) en educación parece ser una constante en nuestro país.

Se puede plantear que los resultados anteriores son consecuencia de antiguas y equivocadas políticas que sólo ahora comienzan a corregirse. Pero los Gráficos 7 y 8 sugieren que nuestros actuales estudiantes están lejos de alcanzar rendimientos satisfactorios. El primero de esos gráficos presenta un ajuste entre ingreso per cápita y resultados en la prueba PISA. Ésta es una prueba de habilidades lectoras aplicada a estudiantes de 15 años, representativos de los países que participaron en el estudio. Este examen fue desarrollado por expertos reunidos por la OECD en función de lo que se estima son las habilidades lectoras que deben tener los estudiantes en nuestro mundo actual. En el gráfico la línea curva y continua representa el mejor ajuste posible entre ingreso per cápita y rendimiento en esa prueba. Esa mejor relación se ajusta por la composición socioeconómica del estudiantado porque, por ejemplo, en Chile la proporción de estudiantes que viene de hogares de bajo nivel socioeconómico es muy superior a la que se observa, digamos, en Canadá. La necesidad de este ajuste reside en 
el hecho de que sabemos que los rendimientos educativos de un joven están fuertemente influidos por el capital cultural y social de la familia, que está correlacionado de manera significativa con el nivel socioeconómico de los hogares. Este argumento se tiene que evaluar con cautela cuando se compara entre países porque hay aquí un grado de endogeneidad que no se puede desconocer. En efecto, es esperable que países con sistemas educacionales mediocres tengan, ceteris paribus, niveles de desigualdad mayores que aquellos que tienen buenos sistemas educacionales, por lo que estos ajustes pueden subestimar los verdaderos déficits educacionales.

El Gráfico $\mathrm{N}^{\circ} 7$ permite concluir que Chile tiene un rendimiento en esta prueba que está por debajo (en un tercio de desviación estándar) del que debería tener si su sistema educativo se comportara como el promedio de los países que participaron en esa prueba. Alcanzar esta meta promedio, aunque es razonable, no deja de ser algo modesto porque hay países que tienen rendimientos que están muy por encima de lo que debería permitirles su realidad económica. Una meta ambiciosa sería alcanzar un rendimiento equivalente al de esos países. Esta ambición no vendría mal si, como hemos intentado sostener, para pasar a nuevos estadios de desarrollo es más imprescindible que nunca contar con un nivel satisfactorio de capital humano.

GRÁFICO N N $^{\circ}$ RESULTADOS EN PRUEBA PISA E INGRESO PER CÁPITA

(Ajustados por nivel socioeconómico del estudiantado)

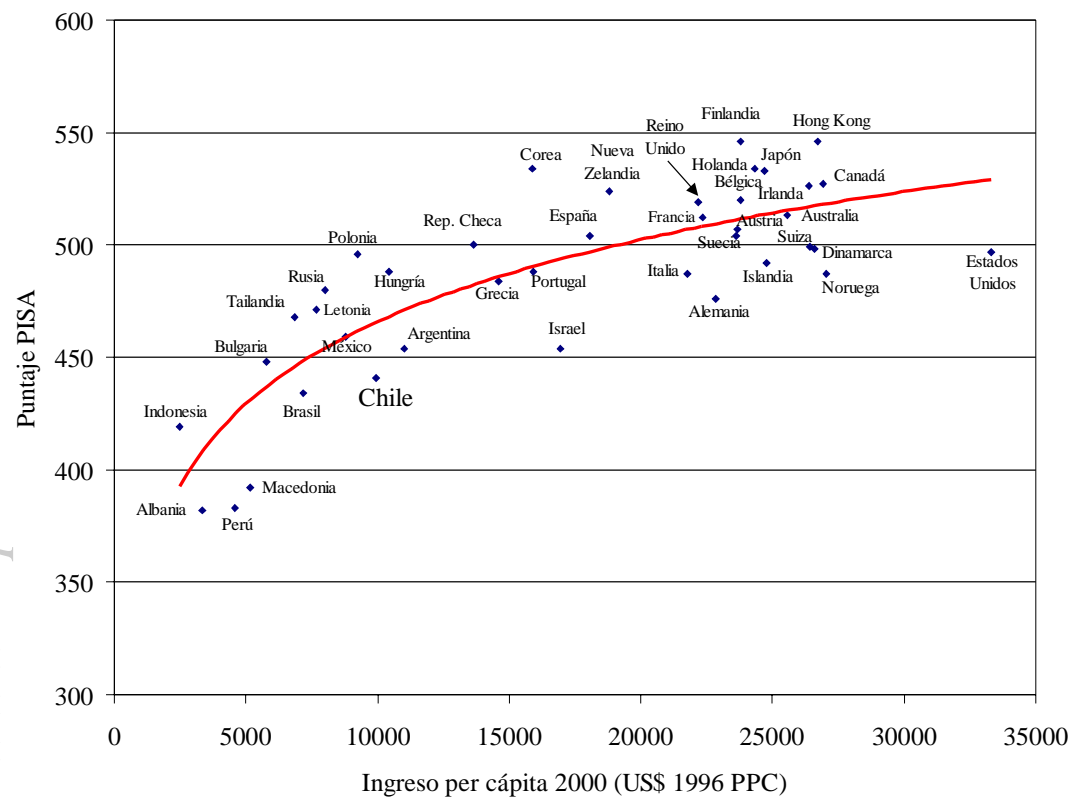


GRÁFICO No 8: RESULTADOS EN PRUEBA TIMSS 2003 E INGRESO PER CÁPITA

(Ajustados por escolaridad de los padres de los estudiantes)

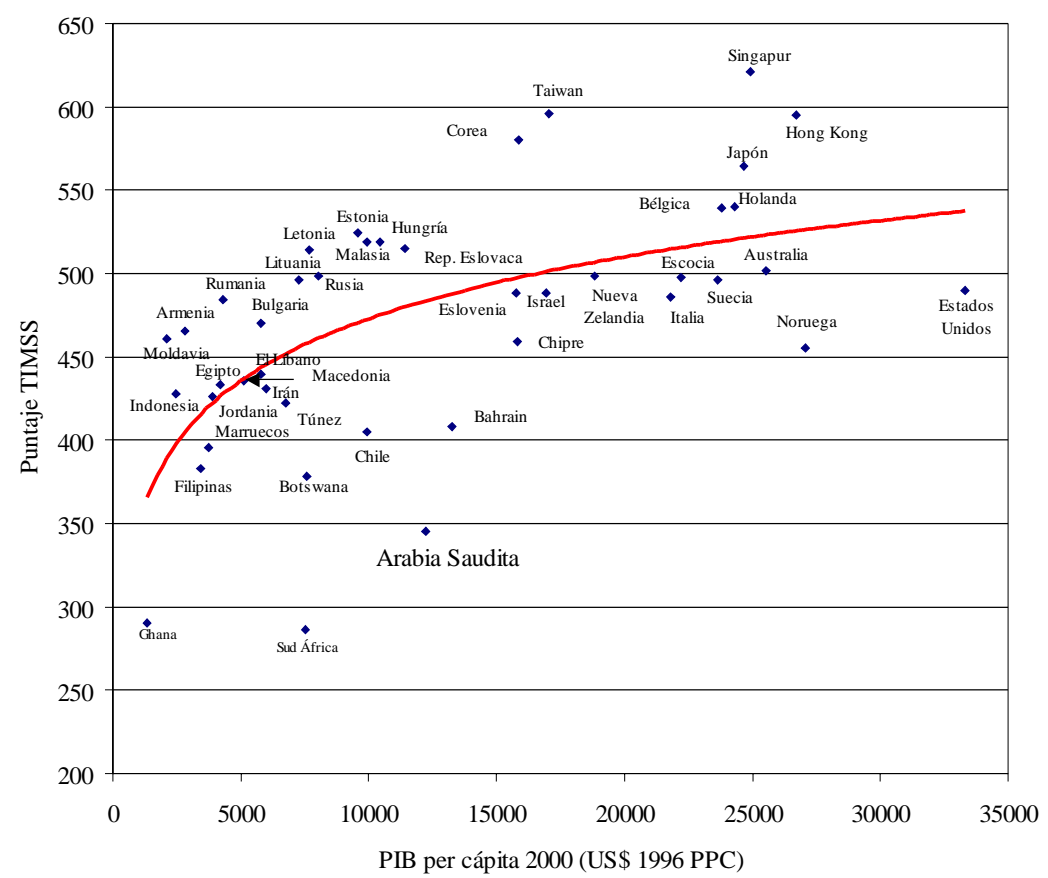

El déficit en la prueba PISA es de una magnitud suficientemente importante como para no ser olvidada en el análisis de las falencias de nuestro sistema educativo. El Gráfico $\mathrm{N}^{\circ} 8$ revela un desempeño aún más deficiente, esta vez en la prueba TIMSS de matemáticas. Esta prueba se aplica a un grupo representativo de estudiantes, dos años menores que los que rinden la prueba PISA, de los países participantes. La responsabilidad de esta prueba recae en el Institute of Educational Achievement con el apoyo del Boston College. Aquí se realiza también un ajuste que intenta aislar el efecto que, sobre los rendimientos educativos, tiene el capital cultural del hogar. En este caso se utiliza la escolaridad de los padres, que probablemente es un mejor indicador que el nivel socioeconómico de los hogares (esa información no está disponible para la prueba PISA). Nuevamente, la línea curva y continua representa el mejor ajuste posible entre rendimiento e ingreso per cápita. En este caso Chile está aún más alejado, que en la prueba anterior, del nivel que le correspondería si se comportara como el promedio de los países que participaron en esa prueba. En este 
caso es un déficit equivalente a dos tercios de una desviación estándar que es una magnitud ciertamente preocupante. Estos promedios, además, esconden el hecho de que alrededor de la mitad de los estudiantes nacionales que participaron en estas pruebas tienen resultados que están en un nivel que los realizadores de estas pruebas consideran básico o incluso inferior a éste.

Este insatisfactorio resultado es sólo la punta del iceberg. Porque, como adelantábamos más arriba, esconden que el desempeño del país es mediocre en todo el rango de la distribución de desempeño. Ésta se presenta en el Gráfico $N^{\circ} 9$ para Chile, y se la compara con las distribuciones de otros países de inferior ingreso per cápita, menor gasto en educación, y de una relativamente alta desigualdad y cobertura en este nivel educativo equivalente a la chilena. Los datos son de la prueba de 1999 dado que al momento de finalizar este artículo aún no estaba disponible la base de datos del año 2003. El gráfico ordena a los estudiantes de menor a mejor desempeño. En particular se presentan los puntajes obtenidos por los estudiantes que están en los percentiles $1,2,3, \ldots 99$. Esto significa que un 1 por ciento, 2 por ciento, ..., un 99 por ciento, respectivamente, de los estudiantes obtuvo puntajes debajo de los que se indican en el gráfico. Por

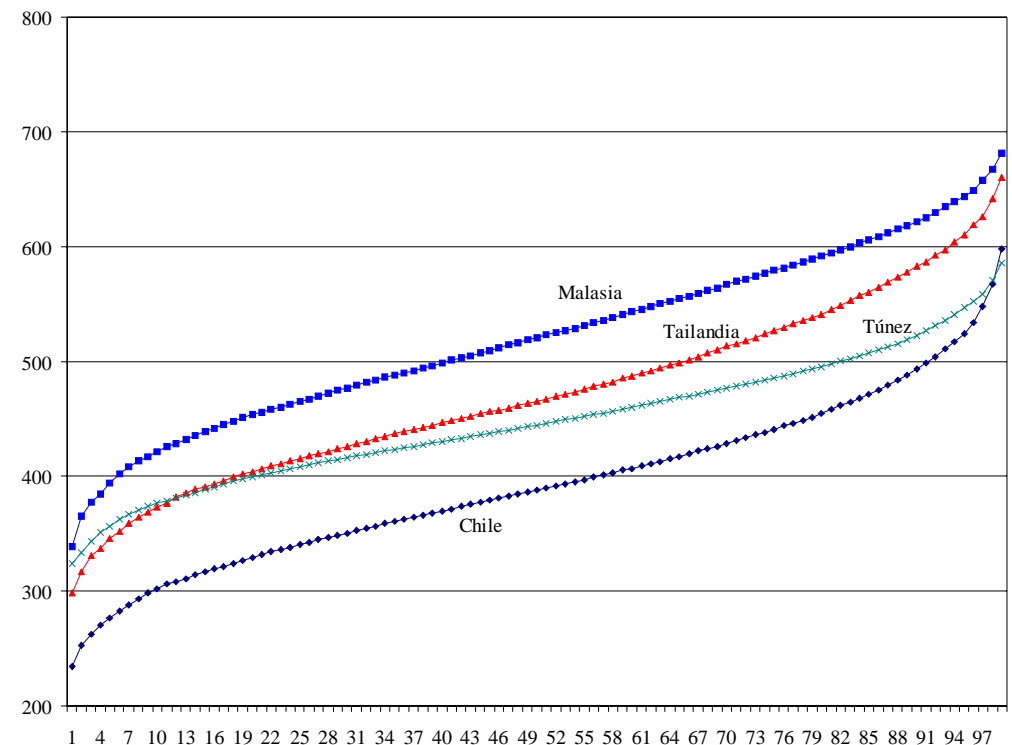


ejemplo, en el caso de Chile, en el percentil 50 se lee un puntaje aproximado de 388 puntos, esto es que un 50 por ciento de los estudiantes obtuvo un puntaje de esa magnitud o inferior al mismo. Si se piensa que esa prueba estaba construida con un promedio internacional de 500 puntos, se aprecia nuevamente el mal desempeño relativo de Chile. De hecho este puntaje se alcanza aproximadamente en el percentil 92 sugiriendo que sólo un 8 por ciento de nuestros estudiantes están por sobre el desempeño internacional en esta prueba.

Por ello es preocupante comprobar que los estudiantes chilenos de mejor rendimiento relativo tienen un desempeño que es parecido a los estudiantes malayos que están en el percentil 40 o 50 de su distribución. Este panorama transmite la sensación, ciertamente desalentadora, de que el país está aún lejos de crear las condiciones en términos de capital humano que se requieren para pasar a etapas siguientes de nuestro desarrollo. Por supuesto, en parte este problema se ha abordado con un acceso creciente a la educación superior, pero ahí también comienzan a existir restricciones. Por una parte, de financiamiento para los estudiantes $\mathrm{y}$, por otra, de las dificultades prácticas que involucra educar en ese nivel a jóvenes con deficiencias en su formación inicial tan marcadas.

Aunque el desafío es de una magnitud enorme tampoco parece razonable plantear que no se puede avanzar en plazos prudentes con los recursos que actualmente disponemos. Países como Malasia y Tailandia, por ejemplo, han logrado en poco tiempo y con déficits iniciales mucho más profundos que los del Chile actual generar sistemas educativos que producen resultados relativamente satisfactorios. Por supuesto que también tienen problemas, pero no hay espacio para el fatalismo. Hacia el futuro es clave desarrollar un marco institucional que asegure un buen aprovechamiento de los recursos y un sistema educativo que en un grado importante esté orientado a los resultados.

\subsection{Un nuevo marco institucional}

Las diferencias en los sistemas educacionales de los países que les va bien (o mal) en el TIMSS son significativas, por lo que tratar de resumir las causas de los buenos (o malos) resultados en unas pocas variables no es una tarea fácil. Pero, si rescatamos los elementos comunes en los diversos países seguramente habremos avanzado en definir esas causas. No es nuestra idea entrar aquí en un análisis exhaustivo de esos elementos aunque sí ofrecer un marco general de análisis. La idea central que subyace en este enfoque es que la institucionalidad educativa del país influye en sus rendi- 
mientos educativos. En particular, cuando se piensa en políticas educativas no se puede olvidar que no hay una relación única entre los esfuerzos educativos y el rendimiento generado. Eso es precisamente lo que se ilustra en la Figura $\mathrm{N}^{\circ} 2$.

FIGURA 2:

RENDIMIENTO EDUCATIVO Y ESFUERZO: LA IMPORTANCIA DEL MARCO INSTITUCIONAL

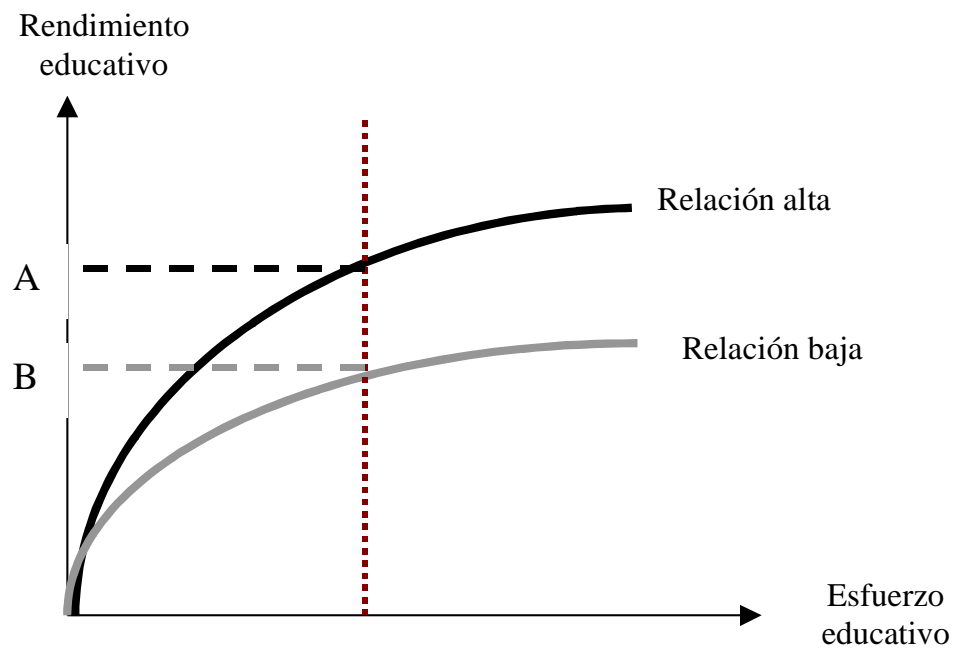

Se puede ver en esa figura que si los esfuerzos realizados son EE*, pueden obtenerse, indistinta aunque no simultáneamente, rendimientos educativos como A y B. Un equilibrio como el de A antes que el de B no es resultado del azar sino que fruto de un diseño adecuado de políticas e instituciones. Es en este ámbito donde hay amplio espacio para corregir lo que se ha venido haciendo hasta ahora en materia educativa. Esto significa que aun en ausencia de nuevos recursos se puede hacer mucho para mejorar la calidad de la educación en Chile. Para ello se requiere mejorar las políticas y corregir falencias institucionales.

En el análisis comparativo uno de los elementos que llama la atención, especialmente porque no aparece con fuerza en los países de bajo desempeño, es que los estudiantes tienen exámenes externos con consecuencias en distintos niveles educativos. De los países con mejor rendimiento, todos, con la excepción de Bélgica flamenca ${ }^{17}$, tienen exámenes externos de evaluación. Estos no son inofensivos sino que tienen efectos

\footnotetext{
${ }^{17}$ En el TIMSS participó sólo la parte flamenca del país.
} 
sobre el desarrollo escolar futuro de los alumnos. Los exámenes importan y son ampliamente difundidos y discutidos en las comunidades escolares. En Chile, en cambio, tenemos exámenes con consecuencias sólo al final del proceso educativo, cuando las posibilidades de corregir el camino andado no existen. Por cierto, estos exámenes no sólo tienen efectos para los estudiantes sino que para los establecimientos educativos. Las consecuencias para las escuelas de resultados poco satisfactorios no se dejan esperar. Hay desde amonestaciones hasta cambio de directores y profesores. Esos países cuentan, entonces, con una institucionalidad que incorpora métodos correctivos en aquellas instituciones donde los resultados educacionales son deficientes. En otras palabras, hay rendición de cuentas y acciones asociadas a esta rendición. Es muy difícil imaginar que en ausencia de estos elementos puedan generarse los suficientes incentivos para conseguir buenos resultados.

Un estudio reciente de Fuchs y Woessmann (2004), utilizando datos de la prueba PISA, estima que alrededor de un 25 por ciento de las variaciones de rendimiento entre 32 países participantes (es la primera versión de la prueba donde no participó Chile) son explicadas por variaciones institucionales, una magnitud que no deja de ser significativa. Este estudio tiene el mérito de controlar por las características socioeconómicas de los estudiantes y la educación y ocupación de los padres. Estas características influyen principalmente en los resultados de la parte lectora de la prueba, aunque menos en matemáticas y ciencias. Entre los elementos institucionales que afectan positivamente el rendimiento de los estudiantes en esta prueba destacan la presencia de exámenes externos. La autonomía de los establecimientos educativos también aporta a mejores rendimientos cuando va acompañada de mayor libertad en el manejo de personal y contratación de profesores así como también en la elección de textos escolares y asignación de recursos al interior del establecimiento. Los efectos de esta autonomía se refuerzan cuando hay exámenes externos.

Nuestros establecimientos educativos están lejos de contar con rendiciones de cuenta mínimas y tampoco gozan de autonomía, a pesar de la supuesta descentralización existente, en las materias que el estudio citado encuentra que afectan positivamente los rendimientos educativos de los estudiantes. Los establecimientos del país, sus directivos y sus profesores viven en la actualidad en un clima educativo de muy poca exigencia y que raya en la impunidad en lo que se refiere al desempeño escolar de los estudiantes. Las clases se interrumpen frecuentemente y los aprendizajes avanzan a un ritmo muy lento. ¡Por supuesto que hay problemas con la formación inicial de los profesores!, pero bajo el marco institucional en 
que se desenvuelve la gran mayoría de los establecimientos del país no está garantizado que buenos profesores obtengan rendimientos sustancialmente mejores.

La creación de un marco institucional o un ambiente educacional en que los establecimientos del país se sientan presionados a hacerlo bien es de una urgencia innegable. En esta dimensión el país está muy rezagado. En su momento el régimen autoritario avanzó en la descentralización del sistema educacional traspasando las escuelas fiscales a las municipalidades y desregulando la oferta educacional. Se cambió, además, la forma de financiamiento de la educación desde un sistema de asignación presupuestaria por escuela a uno de subvención por alumno. Se pensaba que los padres preocupados porque sus hijos recibieran una educación de calidad iban a ir eligiendo las escuelas de mejor rendimiento, desplazando a aquellas de mal rendimiento. Sin embargo, no se creó un sistema que informara a los padres del desempeño de las escuelas. Los padres nunca tuvieron a su disposición un instrumento efectivo para realizar comparaciones entre escuelas. Recién en 1995 se implementó un sistema de información a partir de los resultados de la prueba SIMCE. Este instrumento llega a los padres, sin embargo, en forma muy difusa. No cabe duda que se debe perfeccionar. La información debe ser mucho más precisa, clara y llegar, ojalá directamente, a los padres. Los informes que muchos estados norteamericanos están haciendo llegar a las familias parece un modelo a seguir. Con todo, las posibilidades efectivas de elección en muchas comunas son extraordinariamente limitadas y la oferta, por la heterogeneidad en el tamaño o densidad de las comunas, no es tan dinámica como se preveía en su momento. Además, tampoco los padres eligen necesariamente a los buenos establecimientos. En parte, porque esa decisión depende de una serie de factores. También porque hay dejación. Hay aquí una tensión inevitable entre libertad de elección y tolerancia hacia los establecimientos de bajo desempeño. La existencia de exámenes externos con consecuencias tanto para estudiantes como para establecimientos le quita peso a esa tensión, como sugerimos más adelante.

Por otra parte, la municipalización de la educación no ha dado los frutos esperados. En parte, por los mismos factores mencionados anteriormente. Pero también deben agregarse factores adicionales. En primer lugar, en muchas municipalidades se repitieron, e incluso se agudizaron, los niveles de centralización que se observaban cuando las escuelas eran fiscales. Muchas de las escuelas municipales carecen de una autonomía mínima para llevar adelante la gestión educacional. La legitimidad que les ha otorgado a los alcaldes su elección democrática ha acentuado, en algunos ca- 
sos, esta centralización comunal. En segundo lugar, los alumnos muchas veces se cambian entre escuelas municipales y, por lo tanto, las finanzas municipales no se resienten. Ello diluye los incentivos a mejorar la gestión de las escuelas municipales. Además, casi un $20 \%$ de las comunas del país no tiene ningún tipo de competencia de escuelas privadas. Otro $40 \%$ enfrenta una competencia privada muy limitada. De ahí que no deba extrañar que las matrículas de las escuelas municipales y particulares subvencionadas se hayan mantenido relativamente estables en torno al 57 y $34 \%$, respectivamente, en los últimos 15 años. Las comunas con menor presencia de opciones educacionales son precisamente las comunas más pobres. Así, no es de extrañar que mientras el $75 \%$ de los alumnos del primer quintil de ingreso asisten a una escuela municipal sólo un 48 y un 39\% del tercer y cuarto quintil asisten a ese tipo de establecimiento educacional. Hay un aspecto lateral a esta discusión que no se puede soslayar. Si existe coincidencia en los estudios empíricos en que la escolaridad de los padres o el capital cultural del hogar influye en los rendimientos de los estudiantes, el actual diseño de la subvención es incompatible con esta realidad. Ese antecedente indica que el esfuerzo que se debe hacer para alcanzar un rendimiento educativo determinado es mayor en el caso de un estudiante que proviene de un hogar con un bajo nivel de capital cultural que en el de uno que proviene de otro hogar. Sin embargo, el diseño de la subvención no reconoce este hecho. El resultado es una oferta de menor calidad relativa para los estudiantes de comunas de más bajos ingresos y sin posibilidades reales de que se genere dinamismo en esa oferta.

Pero también la falta de dinamismo y calidad en el sector municipal, y en el país en general, están marcadas por el estatuto docente que protege exageradamente a los profesores municipales en el desempeño de sus funciones. La evaluación docente es un primer paso para ir eliminando los obstáculos que impone esta legislación a la formación de capital humano. Pero es claramente insuficiente. La urgencia en estos momentos es que los rendimientos académicos mediocres no se perpetúen en los establecimientos educativos del país. El estatuto docente y en general el actual marco institucional, aun con evaluación de por medio, no evita esa persistencia. Un fenómeno que en cualquier sistema educacional con estándares mínimos de excelencia sería impensable.

Este estatuto docente indudablemente tiene que flexibilizarse, pero es importante hacer una digresión que se resume el Cuadro $\mathrm{N}^{\circ} 2$ y que indica la evolución salarial de los profesores y del resto de los profesionales de la economía chilena en los últimos 20 años. El ajuste provocado por la crisis económica de 1982-1983 y las posteriores transformaciones reca- 
yeron de manera desproporcionada sobre los profesores. Sus remuneraciones reales descendieron en casi un $38 \%$ en el período comprendido entre 1981 y 1990. La de los profesionales en su conjunto no sólo no cayó sino que se expandió marginalmente. Creo que es inevitable que este tipo de ajustes "dispare de vuelta". Fue un error aprobar el estatuto docente en la forma que se aprobó, pero su origen se comenzó a sembrar en los 80 .

CUADRO No 2 : $\quad$ ÍNDICE DE REMUNERACIONES REALES

\begin{tabular}{lrc}
\hline & Profesores & Profesionales \\
\hline & & \\
1981 & 100,0 & 100,0 \\
1990 & 62,4 & 101,7 \\
1996 & 84,5 & 114,1 \\
2000 & 115,1 & 132,0 \\
2002 & 149,2 & 143,2 \\
& 165,5 & 147,3 \\
\hline
\end{tabular}

Fuente: INE y MINEDUC.

Pero, más allá de esta digresión, no parece razonable que un sistema educacional en el cual los establecimientos, sus directivos y sus profesores son finalmente los responsables del rendimiento de los alumnos mantenga un estatuto docente tan anacrónico como el que Chile presenta. Por supuesto, toda modificación de este estatuto en la dirección de lo que aquí se ha manifestado supone enfrentar al gremio de los profesores. Ello no es una tarea fácil. Es un grupo social significativo que goza de una alta credibilidad. Una encuesta del Departamento de Sociología de la Universidad Católica los ubicaba entre los profesionales que más confianza despiertan en la población. Por lo mismo sus movilizaciones son tremendamente efectivas. Pero ese no es el problema, sí lo es la enorme capacidad que tienen para identificar sus propios intereses con los intereses del país. Y aquí el camino, tal como hemos planteado hasta ahora, sigue siendo el desarrollo de instituciones y políticas que de manera impersonal aseguren que frente a un mal desempeño de los establecimientos educativos habrá espacio para tomar medidas que permitan que la inercia de rendimientos deficientes pueda ser contrarrestada.

Este desarrollo institucional debe recoger el hecho de que al final los cambios tienen que venir de los establecimientos y de las salas de clases. Hay más probabilidades de lograr una mejor educación si se deja a las comunidades locales ensayar con mayor libertad. Los resultados del 
trabajo de Fuchs y Woessmann, antes mencionados, avala este camino Pero esos "ensayos" tienen que ser evaluados. De ahí que los establecimientos deban rendir cuentas frente a la comunidad escolar. Esa rendición debe, en primer lugar, dar cuenta de los resultados académicos. Para ello deben mantenerse evaluaciones externas exigentes tipo SIMCE. Sería extremadamente importante, como sucede en casi todos los países que tienen buenos rendimientos educacionales, que estos exámenes externos afectarán de alguna manera el paso del alumno al nivel educacional siguiente de educación o que entregaran algún tipo de certificación de habilidades. Una medida modesta pero poderosa sería que esta prueba se tradujese en una nota, por ejemplo, equivalente al $25 \%$ de la nota final en la disciplina en la que se rinde el examen. Esto, además, ayudaría a las escuelas a definir más precisamente sus estándares internos.

Parece recomendable evitar a toda costa la persistencia de los malos resultados. ¿Cómo hacer operativo ese marco institucional? Hemos propuesto en Beyer (2001) algunos caminos. Entre éstos, que los padres puedan "intervenir" las escuelas con rendimientos deficientes. Esta intervención de los padres en las escuelas de sus hijos se puede combinar con diversos aspectos específicos que habría que ensayar más cuidadosamente. Por ejemplo, se podría permitir a los padres delegar la administración de las escuelas en instituciones especializadas como fundaciones, universidades o sostenedores privados de buen rendimiento. Es fundamental que esas instituciones se comprometan con metas específicas y se sometan al escrutinio público que los padres demanden.

Este esquema no es propicio para establecimientos particulares subvencionados sin que ello se transforme en una limitación del derecho de propiedad. Pero entre estos también existen establecimientos de resultados persistentemente mediocres. En estos casos deben aplicarse criterios distintos para generar esa presión. Una posibilidad razonable y de aplicación general es establecer contratos de desempeño para cada uno de los establecimientos que recibe recursos públicos. El incumplimiento de estos contratos pone en riesgo la elegibilidad de ese establecimiento para recibir la subvención educacional. Este contrato de desempeño debe reconocer la autonomía del establecimiento para definir sus procesos pedagógicos y debe concentrarse en la consecución de metas precisas en períodos determinados. El contrato debe reconocer el punto de partida del establecimiento y no imponer metas inalcanzables, pero éstas deben ser exigentes. Para evitar arbitrariedades en la definición de estos contratos la contraparte que vela por el interés público debe ser una institución autónoma del poder político y altamente profesional. Para elaborar este contrato los estableci- 
mientos deberían poder acceder a fondos concursables que les permitan abordarlos de la mejor manera posible. La posibilidad de que se suspenda la subvención para los establecimientos de resultados deficientes es polémica, pero es apremiante contar con un marco institucional que asegure no sólo un buen uso de los recursos sino que también esté orientado en un grado importante hacia resultados. Además, parece indispensable velar por la mejor educación posible para niños y jóvenes. En este contexto no parece que requisitos mínimos de desempeño afecten la libertad de elección de las familias en el campo educacional. La existencia de establecimientos más responsables de los resultados académicos de sus alumnos es imprescindible si se quiere generar una dinámica educacional virtuosa. Por supuesto, también involucra riesgos. Desde luego, para mostrar rápidamente resultados, los establecimientos podrían desplazar a los alumnos de menor rendimiento. Pero hay maneras de minimizar este riesgo como los exámenes de "valor agregado". Además, los beneficios potenciales de un sistema educacional más responsable y transparente son tan significativos que, de todas maneras, vale la pena correr este riesgo.

\section{A modo de conclusión}

He intentado sostener en este artículo que Chile está viviendo su momento de mayor desigualdad y que, en cierta medida, ello era inevitable como consecuencia del patrón de desarrollo subyacente que es resultado de sus dotaciones de factores productivos. Al mismo tiempo he dejado entrever un grado importante de optimismo respecto de la evolución futura de la desigualdad. Estamos a las puertas de pasar a un estadio de reducción en esas desigualdades. Para ello es indispensable que podamos allegar más capital humano a la economía.

Pero también necesitamos asegurar un fuerte crecimiento en la productividad que invite a la acumulación de capital tanto físico como humano. He sugerido, además, que ambos fenómenos están más entrelazados de lo que puede pensarse. Sin ese capital humano no sólo se hará muy difícil atraer las tecnologías que necesitamos para pasar a ese nuevo estadio de desarrollo sino que tampoco podremos reasignar nuestros recursos productivos para asegurar esas ganancias de productividad. Por supuesto, para que éstas sean posibles se requiere una economía competitiva, buenas instituciones y también políticas adecuadas. Muy resumidamente, se requiere un ambiente que no incentive las inercias, y que asegure dinamismo y la posibilidad de reasignar con rapidez y sin pérdidas de eficiencia los recursos productivos. 
Es precisamente en esta dirección que nos tenemos que mover en educación. Ésta tiene resultados mediocres y se desenvuelve en un marco institucional donde los incentivos vigentes no aseguran una orientación que permita ser optimista respecto de mejoras futuras. Hay persistencia e inercia en los resultados educativos. Hay que avanzar hacia un marco institucional distinto que ponga los aprendizajes y destrezas de los estudiantes en el centro de las consideraciones pedagógicas. Ello permitirá ir acumulando el capital humano necesario para seguir aumentando nuestro nivel de desarrollo y reducir las desigualdades que tanto preocupan.

\section{ANEXo \\ PRODUCTIVIDAD DEL GASTO EN EDUCACIÓN}

Los intentos por medir el precio y la productividad del sector educación y, en general, de los servicios no es una tarea fácil. Proponemos, sin embargo, una metodología simple para avanzar en esta tarea. Suponemos que el precio de la educación $\left(\mathrm{P}_{\mathrm{sq}}\right)$ es igual al gasto en educación $\left(\mathrm{G}_{\mathrm{s}}\right)$, dividido por el número de alumnos (A), corregido por un índice de calidad $\left(\mathrm{I}_{\mathrm{q}}\right)$ de modo que

$$
\mathrm{P}_{\mathrm{sq}}=\mathrm{G}_{\mathrm{s}} /\left(\mathrm{A} * \mathrm{I}_{\mathrm{q}}\right)=\mathrm{P}_{\mathrm{s}} *\left(1 / \mathrm{I}_{\mathrm{q}}\right)
$$

$\mathrm{P}_{\mathrm{s}}$ correspondería al precio de la educación si la calidad se hubiese mantenido constante. Como el aumento en el gasto en educación puede haber elevado la calidad de la educación, un incremento en el gasto por alumno no necesariamente sugiere un aumento en el precio de la educación. La importancia de definir adecuadamente el precio de la educación radica en que, usando el modelo de costo de síndromes sugerido por Baumol (1967), se puede evaluar a partir de los cambios en el precio relativo de la educación los cambios en la productividad del sector educación (sobre este modelo véase también Krueger, 2001; Gundlach et al., 2001, realizan este ejercicio para los países de la OECD). Se supone que el único factor de producción es trabajo (L) y que existen dos sectores: educación (S) con una tasa de crecimiento de la productividad de $\mathrm{z}_{\mathrm{S}} \mathrm{y}$ resto $\mathrm{R}$ con una tasa de crecimiento de la productividad de $\mathrm{z}_{\mathrm{R}}$.

El producto en ambos sectores puede ser descrito por una función de producción del tipo

$$
\mathrm{Y}_{\mathrm{it}}=\gamma_{\mathrm{i}} \mathrm{L}_{\mathrm{it}} \exp \left(\mathrm{z}_{\mathrm{i}} \mathrm{t}\right) \mathrm{i}=\mathrm{S}, \mathrm{R},
$$


donde $\mathrm{Y}_{\mathrm{it}}$ es el nivel de producto del sector i en el año $t$; $\gamma$ i es un parámetro de eficiencia específico al sector $i, y L_{i t}$ es la cantidad de trabajo empleada en el sector i en el año t. La productividad marginal en ambos sectores está dada por:

$$
\mathrm{dY}_{\mathrm{i}} / \mathrm{dL}_{\mathrm{i}}=\gamma_{\mathrm{i}} \exp \left(\mathrm{z}_{\mathrm{i}} \mathrm{t}\right) \mathrm{i}=\mathrm{S}, \mathrm{R} .
$$

Si se iguala el valor de las productividades marginales a los salarios tenemos que

$$
\mathrm{W}=\mathrm{P}_{\mathrm{sq}} \gamma_{\mathrm{s}} \exp \left(\mathrm{z}_{\mathrm{s}} \mathrm{t}\right)=\mathrm{P}_{\mathrm{s}}\left(1 / \mathrm{I}_{\mathrm{q}}\right) \gamma_{\mathrm{s}} \exp \left(\mathrm{z}_{\mathrm{s}} \mathrm{t}\right)=\mathrm{P}_{\mathrm{R}} \gamma_{\mathrm{R}} \exp \left(\mathrm{z}_{\mathrm{R}} \mathrm{t}\right)
$$

Se concluye, entonces, que el precio relativo de la educación cumple la siguiente condición

$$
\mathrm{P}_{\mathrm{sq}} / \mathrm{P}_{\mathrm{R}}=\left(\gamma_{\mathrm{R}} / \gamma_{\mathrm{S}}\right) \exp \left(\left(\mathrm{z}_{\mathrm{R}}-\mathrm{z}_{\mathrm{S}}\right) \mathrm{t}\right)
$$

O también,

$$
\mathrm{P}_{\mathrm{S}} / \mathrm{P}_{\mathrm{R}}=\mathrm{I}_{\mathrm{q}}\left(\gamma_{\mathrm{R}} / \gamma_{\mathrm{S}}\right) \exp \left(\left(\mathrm{z}_{\mathrm{R}}-\mathrm{z}_{\mathrm{S}}\right) \mathrm{t}\right)
$$

A partir de aquí se tiene que el cambio porcentual en el precio relativo de la educación equivale a las diferencias sectoriales en el crecimiento de la productividad ajustado por el cambio en la calidad de la educación que ocurre en el tiempo ( $\mathrm{I}_{\mathrm{q}}$ depende del tiempo transcurrido). En efecto,

$$
\frac{\mathrm{d}\left(\mathrm{P}_{\mathrm{S}} / \mathrm{P}_{\mathrm{R}}\right) / \mathrm{dt}}{\mathrm{P}_{\mathrm{S}} / \mathrm{P}_{\mathrm{R}}}=\mathrm{dI}_{\mathrm{q}} / \mathrm{dt}+\mathrm{z}_{\mathrm{R}}-\mathrm{z}_{\mathrm{S}} .
$$

Esto significa que sin cambios en la calidad de la educación, un cambio en el precio relativo de la educación que iguale la tasa de crecimiento de la productividad en el resto de los sectores supone una productividad constante de la educación. Si hay cambios en la calidad de la educación el cambio en el precio relativo de la educación podría ser mayor que el crecimiento en la productividad del resto de la economía, sin que ello reduzca la productividad del sector educación. Empíricamente este modelo se puede reformular para utilizar conceptos más familiares. Específicamen- 
te nos podemos concentrar en el precio de la educación deflactado por el deflactor del PIB y en el crecimiento de la productividad total de los factores. Para ello utilizamos dos ecuaciones adicionales. El nivel de precios del PIB puede plantearse como

$$
\mathrm{P}_{\mathrm{PIB}}=\mathrm{P}_{\mathrm{sq}}{ }^{(\mathrm{YS} / \mathrm{Y})} \mathrm{P}_{\mathrm{R}}(\mathrm{YR} / \mathrm{Y})
$$

donde $\mathrm{Y}_{\mathrm{i}} / \mathrm{Y}$ representa la participación del sector i en el PIB. Se desprende de esto que:

$$
\Delta \mathrm{P}_{\mathrm{s}}-\Delta \mathrm{P}_{\mathrm{PIB}}-\left(\mathrm{Y}_{\mathrm{S}} / \mathrm{Y}\right) \Delta \mathrm{I}_{\mathrm{q}}=\Delta \mathrm{P}_{\mathrm{s}}-\left(\mathrm{Y}_{\mathrm{S}} / \mathrm{Y}\right) \Delta \mathrm{P}_{\mathrm{s}}-\left(\mathrm{Y}_{\mathrm{R}} / \mathrm{Y}\right) \Delta \mathrm{P}_{\mathrm{R}}
$$

por consiguiente:

$$
\begin{aligned}
& \text { (1) } \Delta \mathrm{P}_{\mathrm{s}}-\Delta \mathrm{P}_{\mathrm{R}}=\left(\Delta \mathrm{P}_{\mathrm{s}}-\Delta \mathrm{P}_{\mathrm{PIB}}\right) /\left(\mathrm{Y}_{\mathrm{R}} / \mathrm{Y}\right)-\left(\mathrm{Y}_{\mathrm{S}} / \mathrm{Y}_{\mathrm{R}}\right) \Delta \mathrm{I}_{\mathrm{q}}=\Delta \mathrm{I}_{\mathrm{q}}+\mathrm{z}_{\mathrm{R}}-\mathrm{z}_{\mathrm{S}} \\
& \text { (1') } \Delta \mathrm{P}_{\mathrm{s}}-\Delta \mathrm{P}_{\mathrm{R}}=\left(\Delta \mathrm{P}_{\mathrm{s}}-\Delta \mathrm{P}_{\mathrm{PIB}}\right) /\left(\mathrm{Y}_{\mathrm{R}} / \mathrm{Y}\right)=\left(\mathrm{Y} / \mathrm{Y}_{\mathrm{R}}\right) \Delta \mathrm{I}_{\mathrm{q}}+\mathrm{z}_{\mathrm{R}}-\mathrm{z}_{\mathrm{S}} .
\end{aligned}
$$

Como siempre los $\Delta$ representan tasas de cambio, en este caso anuales. Por otra parte la tasa de crecimiento de la productividad total de factores está dada por

$$
\Delta \mathrm{PTF}=\left(\mathrm{Y}_{\mathrm{S}} / \mathrm{Y}\right) \mathrm{z}_{\mathrm{S}}+\left(\mathrm{Y}_{\mathrm{R}} / \mathrm{Y}\right) \mathrm{z}_{\mathrm{R}}
$$

Reordenando términos se tiene que:

(2) $\mathrm{z}_{\mathrm{R}}-\mathrm{z}_{\mathrm{S}}=\left(\Delta \mathrm{PTF}-\mathrm{z}_{\mathrm{S}}\right) /\left(\mathrm{Y}_{\mathrm{R}} / \mathrm{Y}\right)$.

Reemplazando (2) en (1) y restando $\left(\Delta \mathrm{PTF}+\Delta \mathrm{I}_{\mathrm{q}}\right)$ en ambos lados se tiene:

(3) $\Delta \mathrm{P}_{\mathrm{S}}-\Delta \mathrm{P}_{\mathrm{PIB}}-\Delta \mathrm{PTF}-\Delta \mathrm{I}_{\mathrm{q}}=-\mathrm{Z}_{\mathrm{S}}$.

Esta ecuación nos permite afirmar que un incremento en el precio de la educación deflactado por el deflactor del PIB que vaya más allá del 
incremento en la productividad total de los factores, ajustado por los aumentos en calidad, supone una caída en la productividad de la educación. ¿Cómo obtenemos la información necesaria? El precio de la educación lo estimamos dividiendo el gasto en educación (preescolar, básica, especial, media científico-humanista y media técnico profesional) por la matrícula de niños y jóvenes en establecimientos municipales (fiscales) y particulares subvencionados. Los datos del deflactor del PIB provienen del Banco Central. Los datos de PTF provienen de Roldós (1997) y han sido actualizados usando su metodología para los años 1997 a 2000. Datos de calidad satisfactorios no existen en Chile. De hecho las diversas pruebas de evaluación llevadas a cabo en los últimos años no pueden compararse entre sí (Eyzaguirre y Fontaine, 1999). Cox (2001) sostiene que si se comparan los resultados del SIMCE del año 2000 y de 1997 (ambos de $8^{\circ}$ básico) en los aspectos enfatizados por la reforma educacional, se observan aumentos importantes en la calidad de la educación, del orden de 4,6\% si se toman sus mejores números en el rendimiento de los alumnos en el período (esto sugiere aumentos de calidad del orden de $1,5 \%$ promedio anual). Si se comparan las pruebas SIMCE en los 90 (previo a la estandarización de los puntajes) se puede concluir que hay aumentos máximos en el logro académico del orden de 3,1\% anual. Esto claramente exagera los aumentos de calidad porque la norma fue reduciéndose (sobre este punto véase Eyzaguirre y Fontaine, 1999). También ha habido mejoras en la eficiencia interna del sistema educacional chileno que pueden considerarse como aumentos de calidad. Sin embargo, éstos parecen estar más correlacionados con el crecimiento económico del país. En los últimos 20 años los tiempos de egreso han ido reduciéndose a tasas decrecientes y la retención a $8^{\circ}$ básico y a $4^{\circ}$ medio ha ido aumentando a tasas decrecientes. No consideramos, entonces, la mayor eficiencia interna del sistema como un indicador de calidad. Para nuestra estimación suponemos, por consiguiente, una variación anual en la calidad de la educación de $3,1 \%$ en la primera mitad de los 90. A la segunda mitad de los 90 le agregamos a esta magnitud el 1,5\% anual que reflejaría el desarrollo de las habilidades que la reforma quiere potenciar. Para los 80 la información es aún más escasa. Entre los años 1982 y 1984 una selección aleatoria de escuelas (distinta cada año) rindió la prueba de evaluación de rendimiento escolar (PER). Los rendimientos en cuarto básico se mantienen prácticamente sin variaciones. En $8^{\circ}$ básico se observa un aumento en rendimiento. Las pruebas, sin embargo, no son estrictamente comparables. Para la primera mitad de los 80 suponemos que no hubo cambios en el rendimiento educacional de los alumnos. En la segunda mitad comparamos el resultado de la última PER (1984) con el 
SIMCE de 1988 (son pruebas de $4^{\circ}$ básico). En estricto rigor, esta comparación no se puede hacer, pero como nuestro objetivo es definir órdenes de magnitud, la llevamos adelante. La calidad habría bajado en la segunda mitad de los 80 en $1,3 \%$.

Variaciones promedio anuales

\begin{tabular}{lrrrrr}
\hline & $\begin{array}{c}\text { Precio } \\
\text { Educación }\end{array}$ & Deflactor PIB & PTF & Calidad & $\begin{array}{c}1-2-3-4 \\
\text { Prod. educación }\end{array}$ \\
\hline $1981-85$ & $18,4 \%$ & $23,7 \%$ & $-2,3 \%$ & $0,0 \%$ & $-3,0 \%$ \\
$1986-90$ & $18,1 \%$ & $19,8 \%$ & $2,2 \%$ & $-1,3 \%$ & $-2,7 \%$ \\
$1991-95$ & $25,7 \%$ & $11,1 \%$ & $3,3 \%$ & $3,1 \%$ & $8,2 \%$ \\
$1996-00$ & $16,0 \%$ & $3,5 \%$ & $1,6 \%$ & $4,6 \%$ & $6,7 \%$ \\
\hline
\end{tabular}

Fuente: Véase texto.

\section{REFERENCIAS BIBLIOGRÁFICAS}

Baumol, William: "Macroeconomics of Unbalanced Growth: The Anatomy of Urban Crisis". En American Economic Review, Vol. 57 (junio 1967), pp. 415-426.

Berman, Eli, John Bound y Stephen Machin: "Implications of Skill-Biased Technological Change: International Evidence". En Quarterly Journal of Economics, Vol. 113 (1998), pp. 1245-1279.

Beyer, Harald: "Educación y Desigualdad de Ingresos: Una Nueva Mirada". En Estudios Públicos, 77 (verano 2000), pp. 97-130.

Beyer, Harald, "Falencias Institucionales en Educación: Reflexiones a Propósito de los Resultados del TIMSS”. En Estudios Públicos, 71 (otoño 2001), pp. 5-33.

Beyer, Harald: "Sources of Growth in the Chilean Manufacturing Sector". Mimeo, Centro de Estudios Públicos, 2002.

Beyer, Harald: "Evolution of Productivity Levels since 1960: A World View". Mimeo, Centro de Estudios Públicos, 2003.

Beyer, Harald y Rodrigo Vergara: "Productivity and Economic Growth: The Case of Chile". En Norman Loayza y Raimundo Soto (eds.), Economic Growth: Sources, Trends and Cycles. Santiago: Banco Central, 2003.

Blis, Mark y Peter Klenow: "Does Schooling Cause Growth or the Other Way Around?". En American Economic Review, Vol. 76 (2000), pp. 1072-1085.

Borjas, George, Richard Freeman y Lawrence Katz: "How Much Do Immigration and Trade Affect Labor Market Outcome?”. En Brookings Paper of Economic Activity, Vol. 1 (1997), pp. 1-90.

Bourguignon, François y Christian Morrison: "Inequality among World Citizens: 1820-1992". En American Economic Review, Vol. 92 (2002), pp. 727-744. 
Cox, Cristián: "Radiografía a los resultados del SIMCE". Informe $\mathrm{N}^{\circ} 163$ en www.asuntospublicos.org, 15 de diciembre, 2001.

Easterly, William: The Elusive Quest for Growth. Cambridge, Mass.: The MIT Press, 2001.

Eyzaguirre, Bárbara y Loreto Fontaine: “¿Qué Mide Realmente el SIMCE?”. En Estudios Públicos $\mathrm{N}^{\circ} 75$ (invierno 1999), pp. 107-161.

Fuchs, Thomas y Ludger Woessmann: "What Accounts for International Differences in Student Performance? A Reexamination Using PISA Data". Iza Discussion Paper, $\mathrm{N}^{\circ} 1287$, septiembre 2004.

Goldin, Claudia y Lawrence Katz: "The Origins of Technology-Skill Complementarities". En Quarterly Journal of Economics, Vol. 113 (junio 1998), pp. 693-732.

Grossman, Gene y Elhanan Helpman: "Endogenous Innovation in the Theory of Growth". En Journal of Economic Perspectives, Vol. 8 (1994), pp. 23-44.

Gundlach, Erich, Ludger Wossmann y Jens Gmelin: "The Decline of Schooling Productivity in OECD Countries". En Economic Journal, Vol. 111 (mayo 2001), pp. C135-C147.

Krueger, Alan: "An Interview with William J. Baumol". En The Journal of Economic Perspectives, Vol. 15, № 3 (verano 2001), pp. 211-231.

Leamer, Edward: "Paths of Development in the Three-Factor, N-Good General Equilibrium Model”. En Journal of Political Economy, Vol. 95 (1987), pp. 961-999.

Leamer, Edward, H. Maul, S. Rodríguez y P. K. Schott: "Does Natural Resource Abundance Increase Latin America Income Inequality?". En Journal of Development Economics, Vol. 59 (1999), pp. 3-42.

Maddison, Angus: The World Economy: A Millennial Perspective, Paris: OECD.

Pavnick, Nina: "What Explains Skill Upgrading in Less Developed Countries?". En Journal of Development Economics, Vol. 71 (2003), pp. 311-328.

Pritchett, Lant: "Where Has All the Education Gone?". Banco Mundial, Policy Research Working Paper $\mathrm{N}^{\circ} 1581,1997$.

Roldós, Jorge: "El Crecimiento del Producto Potencial en Mercados Emergentes: El Caso de Chile". En Felipe Morandé y Rodrigo Vergara (eds)., Análisis empírico del crecimiento en Chile. Santiago: Centro de Estudios Públicos/ILADES, 1997.

Solow, Robert: "A Contribution to the Theory of Economic Growth". En Quarterly Journal of Economics, Vol. 70 (1956), pp. 65-94. 